\title{
Diffusive fractionation of volatiles and their isotopes during bubble growth in magmas
}

\author{
E. Bruce Watson ${ }^{1}[$
}

Received: 7 February 2017 / Accepted: 17 June 2017 / Published online: 7 July 2017

(C) The Author(s) 2017. This article is an open access publication

\begin{abstract}
Bubbles grow in decompressing magmas by simple expansion and by diffusive supply of volatiles to the bubble/melt interface. The latter phenomenon is of significant geochemical interest because diffusion can fractionate elements and isotopes (or isotopologues) of dissolved components. This raises the possibility that the character of volatile components in bubbles may not reflect that of volatiles dissolved in the host melt over the lifetime of a bubble-even in the absence of equilibrium vapor/melt isotopic fractionation. Recent experiments have confirmed the existence of an isotope mass effect on diffusion of the volatile element $\mathrm{Cl}$ in silicate melt [Fortin et al. (Isotopic fractionation of chlorine during chemical diffusion in a dacitic melt and its implications for isotope behavior during bubble growth (abstract), 2016 Fall AGU Meeting, 2016)], so there is a clear need to understand the efficacy of diffusive fractionation during bubble growth. In this study, numerical models of diffusion and mass redistribution during bubble growth were implemented for both "passive" volatiles-those whose concentrations are generally well below saturation levels - and "active" volatiles such as $\mathrm{CO}_{2}$ and $\mathrm{H}_{2} \mathrm{O}$, whose elevated concentrations and limited solubilities are the cause of bubble nucleation and growth. Both diffusive and convective bubble-growth scenarios were explored. The magnitude of the isotope mass effect on passive volatiles partitioned into bubbles growing at a constant rate $R$ in a static system depends upon $R / D_{\mathrm{L}}, K_{\mathrm{d}}$ and $D_{\mathrm{H}} / D_{\mathrm{L}}$
\end{abstract}

Communicated by Timothy L. Grove.

E. Bruce Watson

watsoe@rpi.edu

1 Department of Earth and Environmental Sciences, Rensselaer Polytechnic Institute, Troy, NY 12180, USA
$\left(K_{\mathrm{d}}=\right.$ bubble/melt partition coefficient; $D_{\mathrm{H}} / D_{\mathrm{L}}=$ diffusivity ratio of the heavy and light isotopes). During convective bubble growth, the presence of a discrete (physical) melt boundary layer against the growing bubble (of width $x_{\mathrm{BL}}$ ) simplifies outcomes because it leads to the quick onset of steady-state fractionation during growth, the magnitude of which depends mainly upon $R \cdot x_{\mathrm{BL}} / D_{\mathrm{L}}$ and $D_{\mathrm{H}} / D_{\mathrm{L}}$ (bubble/ melt fractionation is maximized at $R \cdot x_{\mathrm{BL}} / D_{\mathrm{L}} \approx 0.1$ ). Constant $R$ is unrealistic for most real systems, so other scenarios were explored by including the solubility and EOS of an "active" volatile (e.g., $\mathrm{CO}_{2}$ ) in the numerical simulations. For plausible decompression paths, $R$ increases exponentially with time-leading, potentially, to larger isotopic fractionation of species partitioned into the growing bubble. For volatile species whose isotope mass effects on diffusion have been measured $(\mathrm{Cl}, \mathrm{Li})$, predicted isotope fractionation in the exsolved vapor can be as large as $-4 \%$ for $\mathrm{Cl}$ and $-25 \%$ o for $\mathrm{Li}$.

Keywords Bubble growth · Volatiles · Isotopes · Fractionation

\section{Introduction}

Magmatic volatiles and the isotope ratios of their constituent elements are important tracers of magmatic processes, and can serve as indicators of the abundances and ultimate sources of volatiles in the Earth's interior. Unfortunately, however, volatiles and their isotopes can be fractionated by common magmatic processes, so care must be exercised in drawing conclusions about their significance. In hypabyssal and eruptive systems, bubble formation is a potentially important cause of volatile fractionation. As a consequence of differing solubilities and vapor/melt partition 
coefficients, for example, bubble exsolution can enrich or deplete one volatile relative to another. Bubble formation can also lead to isotopic fractionation of the elemental constituents of specific volatile components (e.g., ${ }^{13} \mathrm{C} /{ }^{12} \mathrm{C}$ in $\mathrm{CO}_{2}$ ) due to equilibrium fractionation between melt and vapor (e.g., Javoy et al. 1978; Gerlach and Taylor 1990; de Moor et al. 2013), possibly compounded by Raleigh distillation effects accompanying bubble nucleation and growth (e.g., Bottinga and Javoy 1989; Vlastélic et al. 2011). An additional and less familiar cause of volatile fractionation in bubbles is that resulting from different diffusivities of volatiles and their isotopes in the melt surrounding a growing bubble (see, e.g., Aubaud et al. 2004). This broad type of diffusive fractionation has been discussed for some types of systems (e.g., growing crystals; Jambon 1980; Watson and Müller 2009), but not in a detailed way for the unique and potentially more complicated case of bubble growth. The purpose of the present contribution is to assess the effectiveness of diffusive fractionation of volatiles and their isotopes during bubble growth for a wide range of growth scenarios.

Bubbles grow in decompressing magmas by simple expansion and by supply of volatiles to the bubble/melt interface by diffusion in the melt. Volatile species that diffuse at different rates are thus expected to fractionate from one another purely as a consequence of varying supply rates to the bubble. This principle applies not only to different volatile compounds (e.g., $\mathrm{CO}_{2}, \mathrm{H}_{2} \mathrm{O}, \mathrm{SO}_{2}$ ), but also to the isotopes of constituent elements of these compounds (and various isotopologues, if the compounds diffuse as molecular units). Recent experimental studies have established the existence of isotope mass effects on diffusion in silicate melts for several cations $\left(\mathrm{Li}^{+}, \mathrm{Mg}^{2+}, \mathrm{Ca}^{2+}, \mathrm{Fe}^{2+}\right.$; Richter et al. 1999; 2003; 2008; 2009; Watkins et al. 2009; 2011), and measurements have recently been extended to the volatile (anionic) element chlorine (Fortin et al. 2016). This knowledge sets the stage for quantitative discussion of diffusive fractionation of volatiles and their isotopes during bubble growth.

Bubble formation and evolution in magmas is a mature and well-understood topic (e.g., Sparks 1978; Proussevitch et al. 1993; Sparks et al. 1994; Toramaru 1989;1995; Proussevitch and Sahagian 1998; Navon et al. 1998; Gardner et al. 1999; Liu and Zhang 2000; Lensky et al. 2004; Gonnermann and Manga 2005, 2007; Zhang 2008; Davydov 2012), and the present study adds little to the general knowledge of bubble growth. However, previous studies have not targeted the specific question of diffusive fractionation of bubble-forming and other volatile components in a comprehensive way. Here, the relevant diffusion/mass-conservation equations are solved numerically to reveal the broad systematics of diffusive fractionation. Two distinct growth scenarios are treated: (1) isolated bubbles in static systems in which the diffusion field surrounding the bubble is unaffected by physical factors; and (2) the generally more realistic case in which the diffusion field is limited by fluid-dynamical factors to a discrete boundary layer of roughly constant width surrounding the bubble. By convention, these two scenarios are referred to as diffusive and convective bubble growth, respectively (see, e.g., Zhang 2008). During convective growth, the diffusion domain of interest is affected by motion of the bubble relative to its surroundings. In both cases it is differences, specifically in diffusion behavior that lead to the fractionation effects of interest in this study.

The simulations described here are simplistic in that the only phenomenon treated directly is diffusion of volatile components into bubbles whose growth rates are prescribed or dictated by an assumed decompression path. No attempt is made to explicitly include factors that can be significant in some bubble-growth scenarios, such as the bubble/melt interfacial energy (which leads to delayed nucleation and overpressure in the bubble), heat of exsolution, melt viscosity, and "PdV" work done during bubble expansion (Sparks 1978; Proussevitch et al. 1993; Prousevitch and Sahagian 1998; Gonnermann and Manga 2005). These factors affect the rate of bubble growth to varying degrees depending on circumstances; however, because most of the present simulations are initiated by assuming a growth rate, the complicating factors listed above are implicitly included in the choice of growth rate. Bubble coalescence can be a major contributor to bubble size in some late-stage magmatic systems, but this phenomenon cannot be simulated in a single-domain, spherical model (although it is probably safe to assume that the vapor composition acquired by single bubbles prior to coalescence is faithfully passed on to a coalesced pair). For the sake of completeness, two distinct "types" of volatiles are recognized here: "passive" volatiles (e.g., $\mathrm{F}, \mathrm{Cl}, \mathrm{N}_{2}$, noble gases, $\mathrm{SO}_{2}$ in some cases) that are partitioned into existing bubbles but play little or no role in nucleation and growth, and "active" volatiles (notably $\mathrm{CO}_{2}$ and $\mathrm{H}_{2} \mathrm{O}$ ) whose high concentrations and limited solubilities are the underlying cause of bubble nucleation and growth during magma decompression, and whose diffusivities influence the rate of bubble growth. In a magma containing a variety of dissolved volatiles, the distinction between these two types of volatiles is not always as clearcut as is assumed for the present simplified treatment.

Equilibrium isotopic fractionation during bubble growth is not addressed in this study. This would be straightforward to include in the models by assigning slightly different bubble/melt partition coefficients to any two isotopes of interest. This added complexity is not considered here to keep the focus on diffusive fractionation specifically (the one exception is in "Fractionation of noble gases during 
growth of $\mathrm{CO} 2$ bubbles", where equilibrium and kinetic aspects of noble gas fractionation are compared).

\section{Numerical simulations}

\section{General approach}

The models consider a single spherical bubble growing at the center of a spherical melt medium (Fig. 1; see Table 1 for a summary of relevant variables). During growth, the bubble/melt interface (at radius $=r_{\mathrm{b}}$ ) moves outward with time according to a specified (or calculated) rate law. The system is subdivided into two domains: one extending from the center of the bubble to its surface and the other, representing the melt, extending radially outward from the bubble/melt interface. Diffusion of the component of interest occurs within the melt domain at a rate specified by a known (or assumed) diffusivity or diffusion law. Diffusion within the bubble is assumed to be infinitely fast,that is, the bubble is considered to be uniform in concentration (composition) at any given instant, even though the concentrations of vapor components change with time. The melt
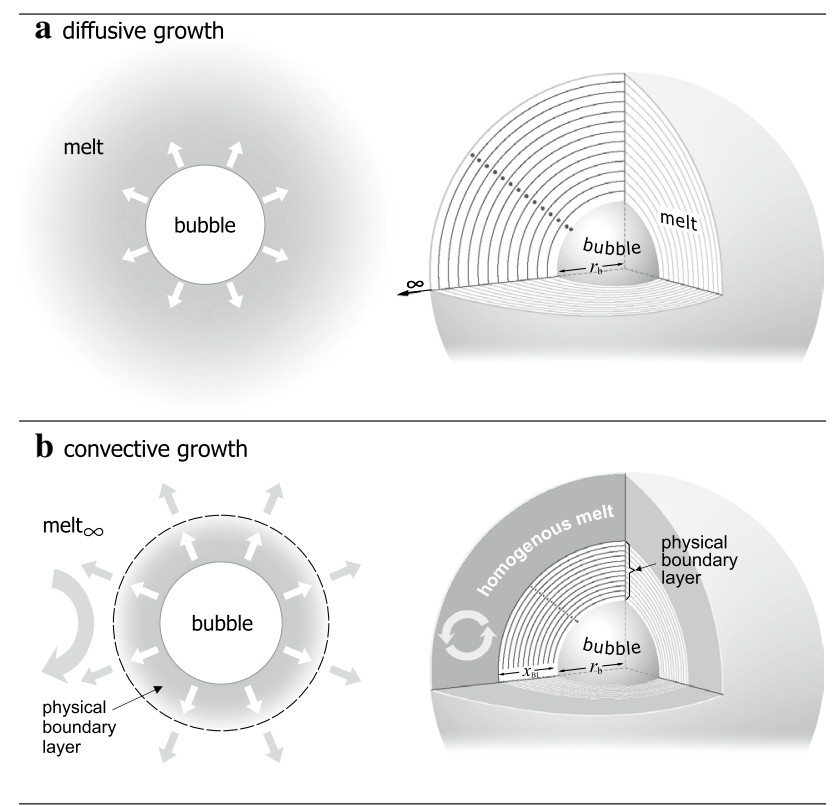

Fig. 1 Schematic representations of bubble growth for the cases of diffusion-control only (a) and diffusion accompanied by bubble motion ("convective" growth; shown in b). Convective growth involves the presence of a physical boundary layer of fixed width that expands with the bubble as shown. The drawings at the left are 2-D representations of the physical system; 3-D versions illustrating the system of nested shells used for the finite difference diffusion calculations are shown on the right. Note that the number of shells is greatly underrepresented in the figure for clarity (several hundred nested shells are used in the finite-difference computer codes). See text for discussion domain is divided into a series of several hundred nested spherical shells; these constitute discrete volume elements between which diffusive exchange occurs. The numerical scheme thus amounts to an explicit finite-difference approach implemented using discrete volume elements (shells). The node representing the radial coordinate of each shell is positioned such that half of the diffusant molecules in the shell are "inboard" and half "outboard" (at distances far from the bubble, this position is close to the radial midpoint of the shell). For diffusive-growth situations, the melt domain is infinite in extent because additional shells are added, if needed, as the diffusion field around the bubble expands. In simulations of convective growth, the outer edge of the fixed boundary layer also constitutes the system boundary; this migrates outward (maintaining a fixed boundary-layer width) as the bubble grows. At each time step, $\delta t$, the bubble is assumed to be in equilibrium with the melt medium at the bubble/melt interface. For passive volatiles, this interfacial equilibrium is defined in terms of a bubble/melt partition coefficient

$K_{\mathrm{d}}=\frac{C_{\mathrm{b}}}{C_{\mathrm{m}}}$

where $C_{\mathrm{b}}$ and $C_{\mathrm{m}}$ represent the volumetric concentrations (molecules or moles $/ \mathrm{m}^{3}$ ) of the species of interest in the bubble and melt, respectively. For some volatiles, the Henry's law constant $K_{\mathrm{H}}$ is conceptually more accurate as a description of the relative concentrations in bubble and melt (see "Fractionation of noble gases during growth of $\mathrm{CO} 2$ bubbles" on noble gases). However, use of $K_{\mathrm{H}}$ would implicitly link the behavior of the element of interest to a decompression path and also to diffusion of other volatiles into the bubble, leading to time-dependent partitioning behavior. Use of a simple (constant) $K_{\mathrm{d}}$ isolates fractionation effects during bubble growth to diffusion specifically. For many elements that prefer vapor to silicate melt (e.g., $\mathrm{Cl}, \mathrm{F}$ and $\mathrm{Li}$ ), $K_{\mathrm{d}}$ is the preferred means of expressing the partitioning (e.g., Webster et al. 2009).

The active volatiles $\mathrm{CO}_{2}$ and $\mathrm{H}_{2} \mathrm{O}$ are treated individually in "Active volatiles: $\mathrm{CO} 2$ and $\mathrm{H} 2 \mathrm{O}$ " and "Natural scenarios involving passive volatiles", and in these cases the interfacial bubble/melt equilibrium is determined by the solubility $C_{\text {sat }}$ of the component of interest $\left(\mathrm{CO}_{2}\right.$ or $\left.\mathrm{H}_{2} \mathrm{O}\right)$ in the melt at the instantaneous temperature and pressure (see "Equations of state, diffusion laws and solubilities" for sources).

During a bubble-growth simulation, the size of $\delta t$ is chosen to remain well below the maximum allowable value for numerical stability in modeling diffusion with the explicit finite-difference method $\left(\delta t_{\max }=\Delta r^{2} / D\right.$, where $\Delta r$ is the inter-node spacing and $D$ is the diffusivity of the species of interest; Crank 1975). In the numerical scheme adopted here, the radial coordinates of the mass-centered nodes 
Table 1 Summary of symbols and their meanings

\begin{tabular}{|c|c|}
\hline Symbol & Definition \\
\hline$A_{i}$ & Surface area of finite-difference shell $i\left(\mathrm{~m}^{2}\right)$ (see Fig. 1) \\
\hline$A_{\mathrm{b}}$ & Surface area of bubble $\left(\mathrm{m}^{2}\right)$ \\
\hline$B$ & A constant \\
\hline$C_{\mathrm{b}}$ & Concentration in the bubble $\left(\right.$ moles $\left./ \mathrm{m}^{3}\right)$ \\
\hline$C_{\mathrm{m}}$ & Concentration in the melt $\left(\mathrm{moles} / \mathrm{m}^{3}\right)$ \\
\hline$C_{\text {sat }}$ & Solubility of a volatile component in the melt (refers to $\mathrm{H}_{2} \mathrm{O}$ and $\mathrm{CO}_{2}$ ) \\
\hline$C_{i}$ & Diffusant concentration in shell $i$ \\
\hline$C_{\mathrm{eq}}$ & Concentration of volatile in the melt in equilibrium with the bubble \\
\hline$C_{\infty}$ & Diffusant concentration far from the bubble (beyond diffusive boundary layer) \\
\hline$C_{\mathrm{H}} / C_{\mathrm{L}}$ & Concentration ratio of heavy and light isotopes of a particular element \\
\hline$\Delta C /\left.\Delta r\right|_{\text {int }}$ & Concentration gradient in the melt at the bubble interface \\
\hline$D$ & Diffusivity $\left(\mathrm{m}^{2} / \mathrm{s}\right)$ \\
\hline$D_{\mathrm{H}}$ & Diffusivity of the heavier of two isotopes under comparison $\left(\mathrm{m}^{2} / \mathrm{s}\right)$ \\
\hline$D_{\mathrm{L}}$ & Diffusivity of the lighter of two isotopes under comparison $\left(\mathrm{m}^{2} / \mathrm{s}\right)$ \\
\hline$D_{\mathrm{c}}$ & Compositional diffusivity of the melt (of melt-structure controlling component) \\
\hline$d$ & Bubble diameter \\
\hline$\delta \mathrm{t}$ & Time step in finite-difference numerical scheme \\
\hline$\delta_{\mathrm{H}}$ & Deviation of the isotope ratio (heavy/light) from the far-field value in the melt (\%o) \\
\hline$\delta_{\max }$ & Maximum fractionation achieved in a bubble for a given growth scenario $(\%)$ \\
\hline$\delta_{\mathrm{ss}}$ & Steady-state fractionation achieved in the bubble during convective growth (\%o) \\
\hline$\delta_{\mathrm{ss}(0.1)}$ & Steady-state fractionation in bubble for convective growth when $R \cdot x_{\mathrm{BL}} / D=0.1(\% o)$ \\
\hline$g$ & Gravitational acceleration \\
\hline$J_{\text {in }}$ & Flux of diffusant atoms into a specified shell volume $\left(\right.$ atoms $\left./ \mathrm{m}^{2} \cdot \mathrm{s}\right)$ \\
\hline$J_{\text {out }}$ & Flux of diffusant atoms out of a specified shell volume $\left(\right.$ atoms $\left./ \mathrm{m}^{2} \cdot \mathrm{s}\right)$ \\
\hline$J_{\text {int }}$ & Flux through the bubble/melt interface (atoms $\left./ \mathrm{m}^{2} \cdot \mathrm{s}\right)$ \\
\hline$K_{\mathrm{d}}$ & Bubble/melt partition coefficient, $C_{b} / C_{m}$ \\
\hline$K_{\mathrm{H}}$ & Henry's law constant $=C_{m} / p_{i}$ where $p_{i}$ is the partial pressure of $i$ in the vapor \\
\hline$\mu$ & Melt viscosity \\
\hline$n_{\mathrm{i}}$ & Number of diffusant atoms in volume $i$ \\
\hline$n_{\mathrm{b}}$ & Number of diffusant atoms in bubble \\
\hline$P e$ & Péclet number $=U \cdot d / D_{\mathrm{c}}($ dimensionless $)$ \\
\hline$P$ & Total pressure on the system (bars) \\
\hline$p_{\mathrm{i}}$ & Partial pressure of gas species $i$ in a bubble \\
\hline$R$ & Growth rate of bubble $(\mathrm{m} / \mathrm{s})$ \\
\hline$r_{\mathrm{i}}$ & Radial coordinate of shell $i(\mathrm{~m})$ \\
\hline$r_{\mathrm{b}}$ & Bubble radius $(\mathrm{m})$ \\
\hline$\Delta r$ & Inter-node spacing in finite-difference numerical scheme \\
\hline$\rho_{\mathrm{m}}$ & Melt density $\left(\mathrm{g} / \mathrm{cm}^{3}\right)$ \\
\hline$\rho_{\mathrm{b}}$ & Bubble density $\left(\mathrm{g} / \mathrm{cm}^{3}\right)$ \\
\hline$t$ & Time (s) \\
\hline$U$ & Ascent velocity of bubble \\
\hline$x_{\mathrm{BL}}$ & Width of diffusive boundary layer in convective growth case (m) \\
\hline
\end{tabular}

remain fixed, with bubble growth accommodated by shrinking and ultimately "consuming" the innermost shell in the melt as required. The starting point for all simulations is a pre-nucleated bubble of $10-30 \mu \mathrm{m}$ radius, which is initially in equilibrium with the surrounding melt (the vapor initially present in the bubble is quickly overwhelmed by influx from the melt, so the choice of initial radius has a negligible effect on outcome as long as it is small relative to the amount of growth simulated). Bubble growth with accompanying diffusion is then monitored in small time increments $\delta t$ during which the following steps are executed: (1) the bubble expands-either at a preset growth rate $R$ or by a small decrement in pressure leading to a density reduction specified by the appropriate equation of 
state (for $\mathrm{CO}_{2}$ or $\mathrm{H}_{2} \mathrm{O}$ ); (2) the innermost shell of the melt domain is reduced accordingly; (3) the component of interest is redistributed between the bubble and the innermost shell as dictated by $K_{\mathrm{d}}$ (or $C_{\text {sat }}$ ) and the relevant diffusivity; and (4) gradients and fluxes between adjacent shells are computed and the resulting concentration changes applied. Specifically, the change in number of diffusant atoms in shell $i$ during time step $\delta t$ is given by

$\delta n_{i}=\left(J_{\text {in }} \cdot A_{i-1}-J_{\text {out }} \cdot A_{i}\right) \cdot \delta t$

where $J$ is the diffusive flux into or out of the shell and $A$ is the area of the surface through which that flux occurs. If the instantaneous fluxes are expressed in terms of diffusivities and concentration differences between adjacent shells (i.e., $\left.J=-D \frac{\Delta C}{\Delta r}\right)$, then

$\frac{\delta n_{i}}{\delta t}=-D\left\{\left(\frac{C_{r_{i}}-C_{r_{i}-1}}{r_{i}-r_{i-1}}\right) \cdot A_{i-1}-\left(\frac{C_{r_{i}}-C_{r_{i}+1}}{r_{i}-r_{i+1}}\right) \cdot A_{i}\right\}$,

where $C_{r_{i}}$ represents the concentration of diffusant in shell $i$ at radial position $r$. During the same time step, the number of molecules in the bubble $\left(n_{\mathrm{b}}\right)$ changes by

$\delta n_{\mathrm{b}}=J_{\mathrm{int}} \cdot A_{\mathrm{b}} \cdot \delta t$,

where $A_{\mathrm{b}}$ is the bubble area and $J_{\text {int }}$ is the instantaneous flux through the bubble/melt interface. This interface flux is computed as

$J_{\text {int }}=-\left.D \frac{\Delta C}{\Delta r}\right|_{\text {int }}=-D \frac{C_{\mathrm{eq}}-C_{r_{1}}}{r_{\mathrm{b}}-r_{1}}$,

where $r_{\mathrm{b}}$ is the bubble radius, $r_{1}$ is the radial position of the innermost node in the melt diffusion field, $C_{r 1}$ is the diffusant concentration at that node, and $C_{\mathrm{eq}}$ is the equilibrium concentration of diffusant in the melt at the bubble/ melt interface. At a given pressure and temperature, $C_{\mathrm{eq}}$ is specified either by the partition coefficient $K_{\mathrm{d}}$ (for passive volatiles) or by $C_{\text {sat }}$ (for active volatiles).

Equation 3 accomplishes the same result as finite-difference solution of the non-steady state diffusion equation in spherical coordinates (Crank 1975):

$\frac{\partial C}{\partial t}=D \frac{\partial^{2} C}{\partial r^{2}}+\frac{2 D}{r} \frac{\partial C}{\partial r}$

Equations 3 and 6 implicitly consider the host melt as the stationary reference frame for diffusion calculations. For moving-boundary problems like bubble growth, it is sometimes more convenient to use the interface as the frame of reference and migrate the diffusion field toward it, which requires a translation term in the diffusion/mass-conservation equation (e.g., Readey and Cooper 1966; see also Zhang 2008). The approach used in the present study (stationary shells that interact by diffusion with a moving bubble/melt interface) is preferred because it involves explicit computation of fluxes between volume elements (shells and bubble) at every time step, so the cumulative effects of diffusive transport can be summed over the course of a simulation, and mass conservation is easily monitored. The scheme is the same as that used by Watson and Müller (2009), who also demonstrated outcomes indistinguishable from those produced by an implicit (Crank-Nicholson), migrating-grid approach. All simulations in the present study were confirmed to conserve mass, and to yield results independent of the values of $\delta t$ and $\Delta r$ over reasonable variations in these parameters.

For convective-growth models ("Convective bubble growth (dynamic system)" and "Exsolution of CO2 from MORB"), the growing bubble is assumed to be mantled by a boundary layer whose width is controlled by fluid dynamical effects accompanying motion of the bubble in the melt. In this case, the boundary layer does not expand indefinitely as the bubble grows and diffusion proceeds. This convective bubble-growth situation is readily accommodated in the numerical algorithm described above by holding constant the diffusant concentration at the initial melt value (the far-field concentration) at the outer edge of the boundary layer. This approach is conceptually similar to the simplified bubble-growth equation

$\frac{\mathrm{d} n_{\mathrm{b}}}{\mathrm{d} t}=\frac{4 \pi r_{b}^{2} D\left(C_{\infty}-C_{\mathrm{sat}}\right)}{x_{\mathrm{BL}}}$,

where $r_{\mathrm{b}}$ is the bubble radius, $C_{\infty}$ is the far-field concentration of the volatile component, and $x_{\mathrm{BL}}$ is the width of the fluid dynamical boundary layer (Zhang 2008). This equation is discussed further in "Convective bubble growth (dynamic system)".

\section{Equations of state, diffusion laws and solubilities}

The simulations described in "Active volatiles: $\mathrm{CO} 2$ and $\mathrm{H} 2 \mathrm{O}$ " and "Natural scenarios involving passive volatiles" treat circumstances in which a specific volatile component $\left(\mathrm{CO}_{2}\right.$ or $\left.\mathrm{H}_{2} \mathrm{O}\right)$ has exceeded the saturation level in the melt due to decompression of the system, which leads to immediate bubble nucleation and growth by simple expansion and diffusion of the relevant volatile from the melt into the bubble. Numerical simulation of such cases requires incorporation into the computer code subroutines that efficiently calculate, at each time step, the solubility of the bubble-forming volatile in the melt and its PVT properties in the bubble. Diffusivities may also require continuous recalculation during program execution (to accommodate, for example, changes in $D_{\mathrm{CO} 2}$ with pressure and $D_{\mathrm{H} 2 \mathrm{O}}$ with both pressure and concentration in the melt). In the present study, the PVT properties of $\mathrm{CO}_{2}$ and $\mathrm{H}_{2} \mathrm{O}$ are calculated from subroutines based on Bottinga and Richet (1981) and Halbach and Chatterjee (1982), respectively. Subroutines to 
calculate diffusivities in the melt of $\mathrm{CO}_{2}$ and $\mathrm{H}_{2} \mathrm{O}$ are based on Zhang and Ni (2010), specifically their equation nos. 41 (for $\mathrm{CO}_{2}$ ) and $13 \& 14$ (for $\mathrm{H}_{2} \mathrm{O}$ ). The solubilities of $\mathrm{CO}_{2}$ in basalt and $\mathrm{H}_{2} \mathrm{O}$ in rhyolite are computed in subroutines that incorporate non-linear fits to output from the program VolatileCalc of Newman and Lowenstern (2002).

The simulations involving $\mathrm{CO}_{2}$ in basalt and $\mathrm{H}_{2} \mathrm{O}$ in rhyolite are simplified, in that only one major volatile is treated in each case: $\mathrm{CO}_{2}$ in basalt and $\mathrm{H}_{2} \mathrm{O}$ in rhyolite. In a phase equilibrium sense, this means that the solubility of $\mathrm{CO}_{2}$ or $\mathrm{H}_{2} \mathrm{O}$ alone determines the course of bubble growth. In models that include elemental or isotopic fractionation of trace components ( $\mathrm{Li}, \mathrm{Cl}$ and noble gases), these species are partitioned between the melt and pure $\mathrm{CO}_{2}$ vapor (basalt) or $\mathrm{H}_{2} \mathrm{O}$ vapor (rhyolite). This approach does not accurately represent behavior in magmas because natural systems saturate in a mixed volatile phase; however, the dominant-volatile assumption markedly simplifies the calculations by allowing the solubility relations of the endmember volatiles to drive bubble growth.

\section{Passive volatiles}

\section{Diffusive bubble growth (static system)}

As noted in the introduction, volatiles are designated here as "passive" if they play no role in bubble nucleation and growth but are strongly partitioned into any existing bubbles. Examples include noble gases, $\mathrm{N}_{2}, \mathrm{Cl}, \mathrm{F}$, and $\mathrm{Li}, \mathrm{SO}_{2}$ and $\mathrm{CO}_{2}$ under some circumstances. Lithium and $\mathrm{Cl}$ are imparted special status in this study because these elements are expected to partition into a vapor phase under at least some circumstances, and because the isotope mass effect on diffusion has been characterized in both cases, so model results for isotopic fractionation are more than purely hypothetical. Lithium and $\mathrm{Cl}$ differ in the sense that the latter is a true volatile element (favoring any vapor phase), whereas the former is a fluid-mobile fluxing component.

The approach in this part of the study was to run simulations starting with a wide range of $R / D$ values, where $R$ is the growth rate of the bubble and $D$ is the diffusivity of the passive volatile of interest in the melt (note that $D$ without subscript implicitly refers to the diffusivity of the faster of two diffusants being compared). These are generic models, not intended to simulate any particular melt or volatile, but rather to reveal key variables and relationships. The growth rate $R=\mathrm{d} r_{\mathrm{b}} / \mathrm{d} t$ is assumed to be constant in these models, so the radius of the bubble increases linearly with time. As discussed in "Active volatiles: $\mathrm{CO} 2$ and $\mathrm{H} 2 \mathrm{O}$ ", constant $R$ is not realistic for most bubble-growth scenarios, but it is a starting basis for establishing relationships and revealing dependencies.
Simulations were conducted with both $R$ and $D$ varying over many orders of magnitude, but it quickly became clear that a given $R / D$ ratio produces the same outcome regardless of the individual values of $R$ and $D$ (this was anticipated on the basis of behavior shown by other systems that are conceptually similar; e.g., Smith et al. 1955). Importantly, $R / D$ is not dimensionless; here it is expressed in $\mathrm{m}^{-1}$. Values of the bubble/melt partition coefficient $\left(K_{\mathrm{d}}\right)$ between 10 and 1000 were explored to compare minimally volatile components (e.g., $K_{\mathrm{d}} \sim 10$ ) with highly volatile ones. It will become clear shortly that outcomes for $K_{\mathrm{d}}=100$ and 1000 are not very different, which indicates that any passive volatile that is strongly partitioned into the bubble will exhibit similar behavior [note, again, that $K_{\mathrm{d}}$ is a volume-based quantity: (moles $\left./ \mathrm{m}^{3}\right)_{\text {bubble }} /($ moles/ $\left.\mathrm{m}^{3}\right)_{\text {melt }}$. Diffusivity ratios ranging from 0.001 to 0.998 were explored, but the focus was upon values of 0.950 0.998 , because this is the plausible range of $D$ ratios for isotopes of a single element (in this case the diffusivity ratio is indicated by $D_{\mathrm{H}} / D_{\mathrm{L}}$-that is, heavy over light).

Some key outcomes of simulations targeting diffusioncontrolled growth are shown in Fig. 2, which is aimed specifically at fractionation of the isotopes of a hypothetical volatile component. In this figure, fractionation is expressed using the usual geochemical $\delta$ notation:

$\delta_{\mathrm{H}}=\left\{\frac{\left(C_{\mathrm{H}} / C_{\mathrm{L}}\right)_{\text {bubble }}-\left(C_{\mathrm{H}} / C_{\mathrm{L}}\right)_{\infty}}{\left(C_{\mathrm{H}} / C_{\mathrm{L}}\right)_{\infty}}\right\} \times 1000$

where the subscripted concentrations refer to hypothetical heavy $(\mathrm{H})$ and light $(\mathrm{L})$ isotopes, and $\infty$ indicates the far-field concentration ratio in the melt (which is also the initial ratio in the melt). The panels on the left show the evolution of $\delta_{\mathrm{H}}$ in the bubble as a function of bubble radius for $K_{\mathrm{d}}=1000,100$ and 10 , and for $R / D$ values ranging from 10 to $10^{5} \mathrm{~m}^{-1}$. This $R / D$ range defines the growth region of greatest interest: $R / D>10^{5}$ results in essentially no isotopic fractionation, and $R / D<10$ results in a slow responsewhich means that bubbles must be very large before noteworthy fractionations are achieved. The key aspect of the $\delta_{\mathrm{H}}$ vs. bubble radius curves in Fig. 2 is that $\delta_{\mathrm{H}}$ is expressed as a fraction of the maximum value, $\delta_{\max }$, that is achievable for a given diffusivity ratio $D_{\mathrm{H}} / D_{\mathrm{L}}$. Each of these three diagrams (for $K_{\mathrm{d}}=100,100$ and 10 ) is exactly the same for all plausible values of $D_{\mathrm{H}} / D_{\mathrm{L}}$, but $\delta_{\max }$ depends (linearly) on $D_{\mathrm{H}} / D_{\mathrm{L}}$ as shown in the panels at the right. The selfsimilarity for all values of $D_{\mathrm{H}} / D_{\mathrm{L}}$ makes Fig. 2 completely general. The known $D_{\mathrm{H}} / D_{\mathrm{L}}$ values for ${ }^{37} \mathrm{Cl} /{ }^{35} \mathrm{Cl}(0.995)$ and ${ }^{7} \mathrm{Li} /{ }^{6} \mathrm{Li}(0.967)$ are indicated by dashed (vertical) gray lines traversing the right-hand panels (Fortin et al. 2016; Richter et al. 2003). Note that for a hypothetical bubble/melt $K_{\mathrm{d}}$ of $100, \delta_{\max }$ is approximately $-4 \%$ for $\mathrm{Cl}$ and $-24 \%$ or $\mathrm{Li}$. For $K_{\mathrm{d}}=1000$, the respective $\delta_{\max }$ values for $\mathrm{Cl}$ and $\mathrm{Li}$ are 

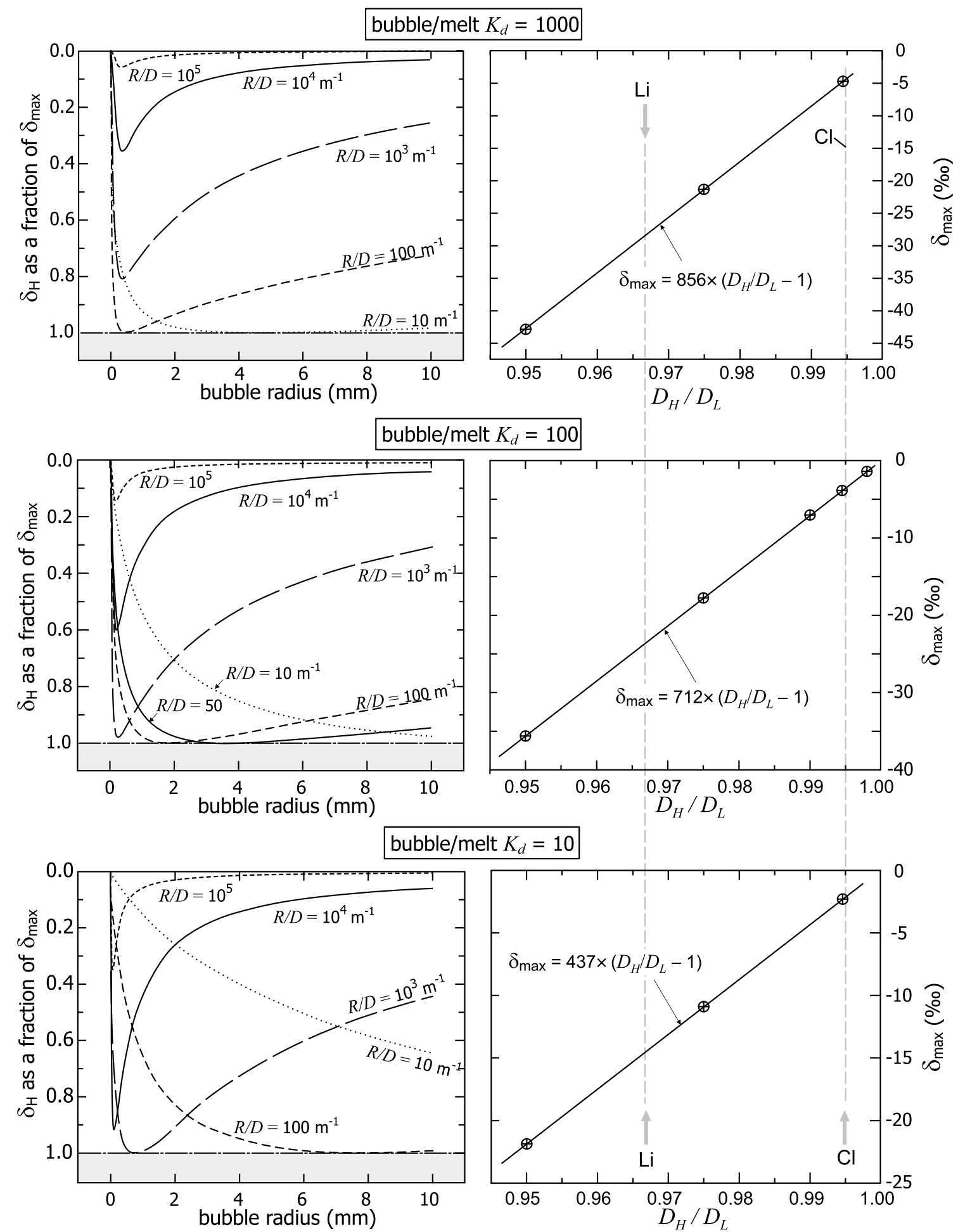

Fig. 2 Heavy isotope depletion (relative to the host melt) in bubbles undergoing diffusive growth with three values of the (volumetric) bubble/melt partition coefficient $K_{\mathrm{d}}(1000,100$ and 10; top to bottom). The panels at the left show $\delta_{\mathrm{H}}$ as a function of bubble radius expressed as a fraction of the maximum value achievable for the $K_{\mathrm{d}}$ under consideration. The maximum value for each $K_{\mathrm{d}}\left(\delta_{\max }\right)$ depends linearly on the diffusivity ratio of the heavy to the light isotope $\left(D_{\mathrm{H}} /\right.$ $\mathrm{D}_{\mathrm{L}}$; see right-hand panels). Note that the difference in behaviors for $K_{\mathrm{d}}=100$ and 1000 is relatively small; $K_{\mathrm{d}}>1000$ leads to outcomes

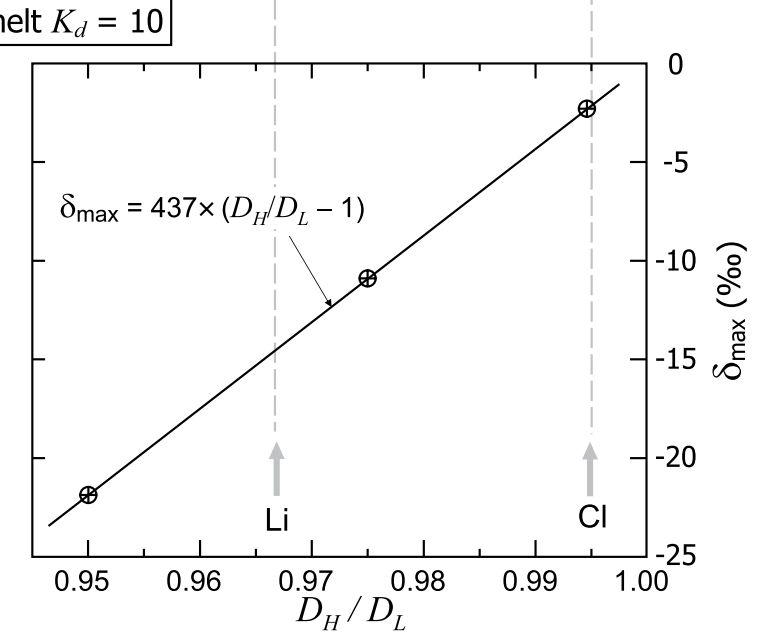

only marginally different from the $K_{\mathrm{d}}=1000$ case. Note also that all $R / D$ values would eventually result in a steady state where the $\delta_{\mathrm{H}}$ of the bubble goes to zero. This is clear for high values of $R / D\left(10^{4}-10^{5}\right.$ $\mathrm{m}^{-1}$ ) and it is true but largely irrelevant for lower $R / D$ values because the bubble would be enormous by the time the steady state was achieved. The symbol $\delta_{\mathrm{H}}$ is standard geochemical "delta" notation, referenced to the isotope ratio of the host melt (Eq. 6). For reference, $D_{\mathrm{H}} / D_{\mathrm{L}}$ values for ${ }^{7} \mathrm{Li} /{ }^{6} \mathrm{Li}$ (Richter et al. 2003) and ${ }^{37} \mathrm{Cl} /{ }^{35} \mathrm{Cl}$ (Fortin et al. 2016) are indicted in the right-hand panels 


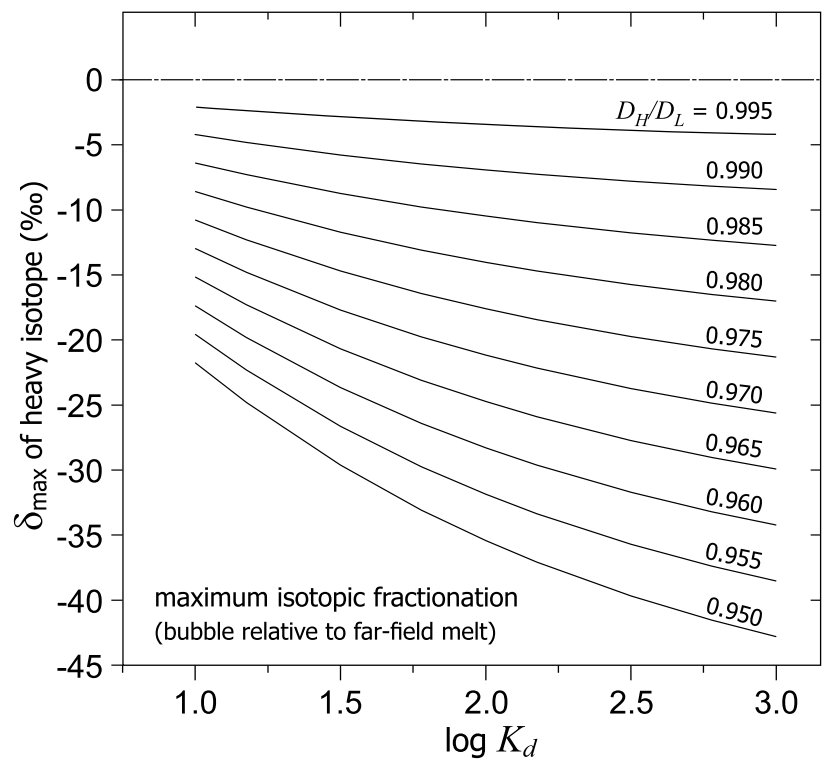

Fig. 3 Summary of $\delta_{\max }$ in the bubble as a function of $K_{\mathrm{d}}$ and $D_{\mathrm{H}} / D_{\mathrm{L}}$ for the range of plausible $D_{\mathrm{H}} / D_{\mathrm{L}}$ values for the isotope mass effect on diffusion in melts. See Fig. 2 and text

$\sim-5$ and $-28 \%$ o ( $\mathrm{Li}$ is examined in more detail in " $\mathrm{Li}$ and $\mathrm{Cl}$ isotopic fractionation during convective growth of $\mathrm{H} 2 \mathrm{O}$ bubbles in rhyolite").

Another noteworthy aspect of Fig. 2 is that $\delta_{\max }$ is never reached for $R / D>1000$, but significant fractionations are nevertheless produced at small bubble radii $(\ll 1 \mathrm{~mm})$. The intermediate $R / D$ value of $100 \mathrm{~m}^{-1}$ could be considered a "sweet spot" for isotope fractionation in the sense that $\delta_{\max }$ is attained at a relatively small bubble radius $(<1 \mathrm{~mm})$. Figure 3 shows the dependence of $\delta_{\max }$ on $K_{\mathrm{d}}$ for the full range of $D_{\mathrm{H}} / D_{\mathrm{L}}$ values that might be anticipated for isotopes of a single volatile element. The bigger picture of diffusive fractionation of volatile components whose diffusivities vary by as much as two orders of magnitude is shown in Fig. 4, where $\delta_{\max }$ is expressed in \% rather than \%o. Diffusive fractionation effects are potentially large, but in natural systems these might be convolved with differences in equilibrium bubble/ melt partitioning (see, e.g., Bottinga and Javoy 1990a).

While Fig. 2 is useful in conveying information about possible diffusive isotopic fractionation that might manifest itself in quenched bubbles in glassy rocks, it provides little insight into why diffusion in the melt leads to these outcomes. It is clear from the figure that a volatile component partitioned into a growing bubble can only be isotopically lighter than its host melt-unless equilibrium fractionation dominates over diffusion effects. Broadly speaking, this is because the lighter (faster) isotope gets to the bubble slightly more efficiently than the heavy isotope. However, the varying shapes of the curves in Fig. 2 suggest a complex interplay between bubble growth and diffusion that can be

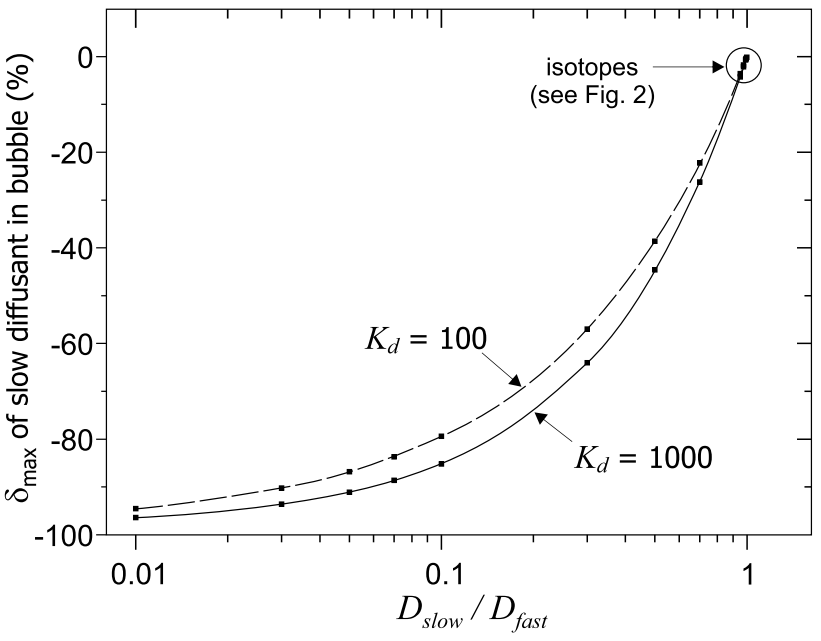

Fig. 4 Maximum depletion of slower diffusant in the bubbleexpressed as $\delta_{\max }$ in percent-for two values of $K_{\mathrm{d}}$ and a slow/fast diffusivity ratio between 0.01 and $1\left(D_{\text {slow }} / D_{\text {fast }}\right.$ is analogous to $D_{\mathrm{H}} / D_{\mathrm{L}}$ for isotopes). The upper right extremes of the curves where $D_{\text {slow }} / D_{\text {fast }}$ approaches 1 represent the plausible realm of isotopes (cf. Fig. 2)

understood only from examination of actual diffusion profiles in the melt that develop near the advancing bubble/ melt interface. Examples are shown in Fig. 5, which depicts $\delta_{\mathrm{H}}$ in the melt as a function of time and distance from the bubble/melt interface for $K_{\mathrm{d}}=100, D_{\mathrm{H}} / D_{\mathrm{L}}=0.995$, and $R / D=100,1000$ and $10,000 \mathrm{~m}^{-1}$. Each panel portrays evolution of the $\delta_{\mathrm{H}}$ profile in the melt as a series of 10 "snapshots" progressing from left to right across the figure as the bubble grows from 1 to $10 \mathrm{~mm}$ in radius (the center of the bubble is at 0 in all cases). For the highest $R / D$, the diffusive boundary layer is narrow $(<1 \mathrm{~mm})$ at all times, with $\delta_{\mathrm{H}}$ showing a sharp upward spike that is almost fully developed before the bubble reaches $1 \mathrm{~mm}$ in radius (cf. the first "snapshot" at the left side of the figure). In this high $R / D$ case, the bubble/melt system quickly approaches a steadystate condition where an unchanging $\delta_{\mathrm{H}}$ profile in the melt is pushed along by the advancing surface of the growing bubble. Near the steady state, no fractionation occurs in the bubble relative to the bulk melt (see Fig. 2) because the isotopically heavy boundary layer against the bubble balances the slower supply of heavy isotope to the interface.

The middle and lower panels of Fig. 5 reveal that lower $R / D$ values lead to quite different behavior. Diffusion in the melt outpaces bubble growth, so large diffusion fields develop around the bubble. The isotopically heavy "bump" in the melt develops more slowly and spreads to widths that quickly exceed the bubble radius. The haloed circle on each figure shows the approximate width of the diffusion field relative to the final $10-\mathrm{mm}$ radius bubble.

An important take-away from Fig. 5 is that the diffusion fields around growing bubbles are generally too 
Fig. 5 Evolution of $\delta_{\mathrm{H}}$ in the melt against the advancing bubble/ melt interface for $K_{\mathrm{d}}=100$ and three values of $R / D$. The center of the bubble is at 0 in all cases; 10 "snapshots" of the melt $\delta_{\mathrm{H}}$ profile are depicted in each panel as the bubble grows to $10 \mathrm{~mm}$ in radius. The lower left termination of each curve is located at the bubble/melt interface. Note that in the fastest growth scenario shown $\left(R / D=10^{4}\right.$ $\mathrm{m}^{-1}$ ) the system quickly approaches a steady state in which the steep heavy-isotope (positive) anomaly is simply pushed along in the melt (without changing shape) and minimal bubble/melt fractionation occurs. The evolution of $\delta_{\mathrm{H}}$ in the melt is dramatically different for smaller $R / D$ values, but it should be noted that preservation of diffusion "haloes" as wide as those shown in the middle and lower panels $\left(R / D=1000\right.$ and $\left.100 \mathrm{~m}^{-1}\right)$ is unlikely due to motion of the bubbles in the melt. The shaded haloes around the circles in each panel illustrate the approximate relative extent of the diffusion fields around the final bubbles (the radius shown is $\sim 1 / 4$ the actual final radius of $10 \mathrm{~mm}$ ). See text for discussion

large to remain undisturbed by motion of the bubble relative to the host melt. This observation paves the way to consider diffusive fractionation during convective bubble growth, where the extent of the diffusive boundary layer is limited by physical factors.

\section{Convective bubble growth (dynamic system)}

As noted earlier, the numerical scheme used in this study is readily adapted to realistic situations where the diffusion field around a growing bubble is truncated by mechanical mixing (erosion) as a consequence of bubble motion in the host melt due to forced convection. In such cases, the width $\left(x_{\mathrm{BL}}\right)$ of the fluid-dynamical boundary layer around the bubble (and hence of the volatile diffusion field) is determined by specific characteristics of the system, including the compositional diffusivity $\left(D_{\mathrm{c}}\right)$ of the melt and the ascent velocity $(U)$ of the bubble. The latter is given by Stokes law:

$U=\frac{g\left(\rho_{\mathrm{m}}-\rho_{\mathrm{b}}\right) d^{2}}{18 \mu}$,

where $g$ is the gravitational acceleration, $d$ is the bubble diameter, $\mu$ is the melt viscosity and $\rho_{\mathrm{m}}-\rho_{\mathrm{b}}$ is the density difference between the melt and the bubble. Once $U$ is constrained, the Péclet number $\left(P e=U \cdot d / D_{\mathrm{c}}\right)$ provides a close approximation to the boundary layer width (Kerr 1995)

$$
x_{\mathrm{BL}} \approx \frac{d}{1+(1+P e)^{1 / 3}}
$$

This relationship indicates a dependence of $x_{\mathrm{BL}}$ on bubble size - both directly and indirectly because $P e$ depends on $d$ (Eq. 10). However, for cases where $P e \gg 1, x_{\mathrm{BL}}$ is independent of bubble size (Kerr 1995), and given by

$x_{\mathrm{BL}} \approx\left(\frac{18 \mu D_{\mathrm{c}}}{g\left(\rho_{\mathrm{b}}-\rho_{\mathrm{m}}\right)}\right)^{1 / 3}$,
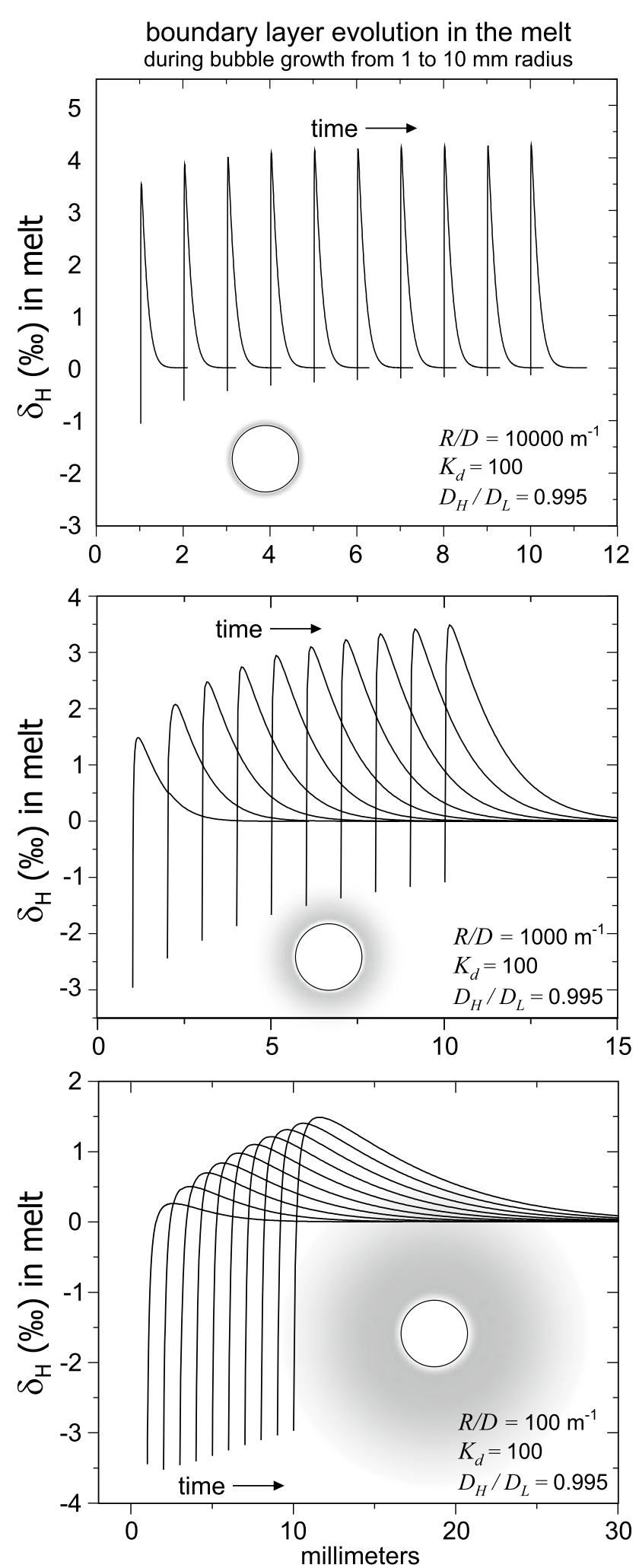

This simplification means that the assumption of constant $x_{\mathrm{BL}}$ during bubble growth is realistic for many circumstances. In a decompressing magma, changing bubble buoyancy $\left(\rho_{\mathrm{b}}-\rho_{\mathrm{m}}\right)$ and size will affect $x_{\mathrm{BL}}$ by a small factor, but not by orders of magnitude. 
Despite the complicating influences on convective bubble growth relative to simple diffusion-controlled growth, the restriction of the diffusive boundary layer to a fixed width leads to two advantages: on the one hand, the key variable in controlling fractionation becomes a dimensionless number $R \cdot x_{\mathrm{BL}} / D$, which is an improvement over the simple $R / D$ ratio because of its generality. In addition, if the boundary layer is thin and of constant width, the system reaches a steady state relatively quickly. For basaltic melts at $1200{ }^{\circ} \mathrm{C}, \mu \approx 100 \mathrm{~Pa} \cdot \mathrm{s}$ (e.g., Villeneuve et al. 2008), $D_{\mathrm{c}} \sim D_{\mathrm{SiO} 2} \approx 2.5 \times 10^{-12} \mathrm{~m}^{2} / \mathrm{s}$ (e.g., Lesher et al. 1996), and $\rho_{\mathrm{m}} \approx 2.7 \mathrm{~g} / \mathrm{cm}^{3}$ (Murase and McBirney 1973; Sparks and Huppert 1984). For a large range of assumed bubble densities $\left(\rho_{b}=0.04-1.0 \mathrm{~g} / \mathrm{cm}^{3}\right)$ and diameters $(d=0.005-1 \mathrm{~cm})$, Eqs. 10 and 11 yield $x_{\mathrm{BL}}$ values within a relatively limited range of $\sim 23-65 \mu \mathrm{m}$. Silicic systems (e.g., rhyolite) are more difficult to constrain in this way because of the pronounced effects of dissolved $\mathrm{H}_{2} \mathrm{O}$ upon both $\mu$ and $D_{\text {c }}$. The substantially higher viscosity of wet rhyolite melt relative to basalt (e.g., $\sim 10^{8}-10^{6} 10 \mathrm{~Pa} \cdot \mathrm{s}$ at $850{ }^{\circ} \mathrm{C}$ for melts with $2-4 \mathrm{wt} \% \mathrm{H}_{2} \mathrm{O}$; Shaw 1963 , 1965; Hess and Dingwell 1996) counteracts to some extent the lower compositional diffusivity, so the range of plausible $\mathrm{Pe}$ values for wet rhyolite overlaps with those for basalt. A rough estimate for $x_{\mathrm{BL}}$ in wet rhyolite is $\sim 25-500 \mu \mathrm{m}$ for the same range of bubble sizes and densities indicated above for basalt. It should be borne in mind that for melts of any composition, the value of $x_{\mathrm{BL}}$ given by Eqs. 10 or 11 is an average for a particular bubble. The actual thickness around the bubble varies because of its upward motion, which causes thinning on the top and a wider "tail" on the bottom (Kerr 1995).

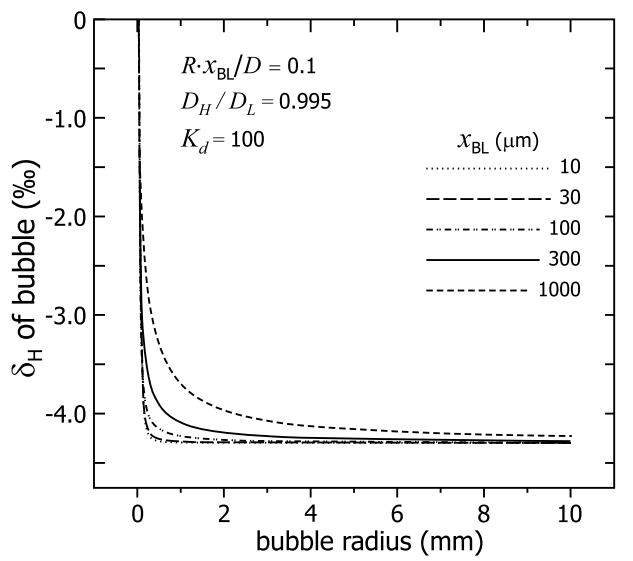

Fig. 6 Evolution of $\delta_{\mathrm{H}}$ in the bubble for two convective-growth scenarios: $R \cdot x_{\mathrm{BL}} / D=0.1$ and $R \cdot x_{\mathrm{BL}} / D=1$ (left and right panels, respectively; $D_{\mathrm{H}} / D_{\mathrm{L}}=0.995$ and $K_{\mathrm{d}}=100$ in both cases). For each value of $R \cdot x_{\mathrm{BL}} / D$, behavior is shown for boundary-layer widths ranging from 10 to $1000 \mu \mathrm{m}$. The key observation is that the bubble-melt system trends toward the same steady-state fractionation for a given
The significance and usefulness of $R \cdot x_{\mathrm{BL}} / D$ is readily appreciated from Fig. 6, which shows $\delta_{\mathrm{H}}$ vs. bubble radius results of numerical simulations conducted with two different values of $R \cdot x_{\mathrm{BL}} / D-0.1$ on the left and 1.0 on the right. Two things are immediately clear: (1) the same steadystate value of $\delta_{\mathrm{H}}$ is reached for a given value of $R \cdot x_{\mathrm{BL}} / D$; but (2) the rate and path of the approach to the steady state depends on the boundary layer width, $x_{\mathrm{BL}}$. The steady state is generally approached after less than a millimeter of growth, except in the case of the widest boundary layer of $1 \mathrm{~mm}$. Given the calculations above, $x_{\mathrm{BL}}$ will rarely exceed $150 \mu \mathrm{m}$ for bubbles in typical magmatic liquids, which means that steady-state fractionation should be established quickly during bubble growth. Accordingly, the remainder of this section will focus on the magnitude of fractionation that applies specifically to the steady state. The important variables are then reduced to just $R \cdot x_{\mathrm{BL}} / D, D_{\mathrm{H}} / D_{\mathrm{L}}$, and $K_{\mathrm{d}}$.

In Fig. 7 , the influence of $R \cdot x_{\mathrm{BL}} / D$ on steady-state fractionation is explored for the specific case where $D_{\mathrm{H}} / D_{\mathrm{L}}=0.995$ and $K_{\mathrm{d}}=100$. It is clear from this diagram that there exists a well-defined window- $\log \left(R \cdot x_{\mathrm{BL}} / D\right) \cong$ -3 to $+0.5-$ where significant isotopic fractionation is expected at the onset of steady-state bubble growth. Fractionation is maximized when $R \cdot x_{\mathrm{BL}} / D$ is close to 0.1 , where the bubble is $\sim 4.3 \%$ o lighter than the melt for the specific values of $D_{\mathrm{H}} / D_{\mathrm{L}}(0.995)$ and $K_{\mathrm{d}}(100)$ used in the simulations. A potentially useful conclusion from Fig. 7 is that diffusive isotopic fractionation is likely to be minimal for very fast bubble growth or when the volatile of interest is a sluggish diffuser (e.g., $\mathrm{SO}_{2}$; Baker and Rutherford 1996). For $R \cdot x_{\mathrm{BL}} / D>3$, bubble growth overwhelms any diffusive fractionation effect in the melt. For $R \cdot x_{\mathrm{BL}} / D<0.001$, on the

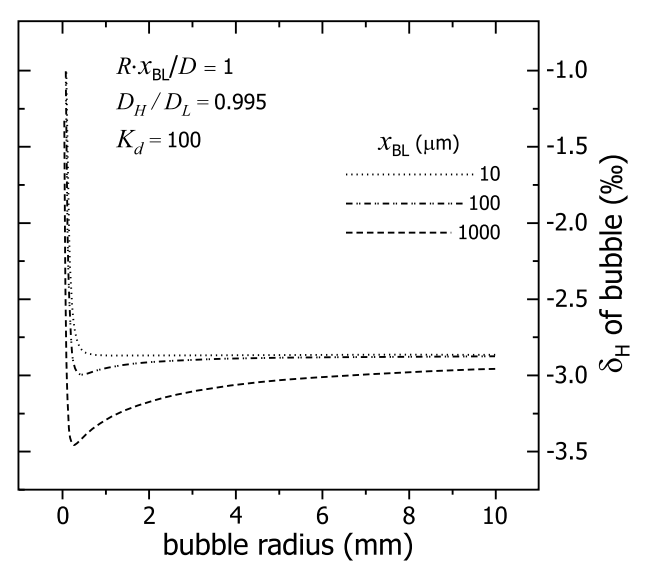

value of $R \cdot x_{\mathrm{BL}} / D$, but that the path to the steady state depends critically upon $x_{\mathrm{BL}}$. Thin boundary layers (a few $10 \mathrm{~s}$ of $\mu \mathrm{m}$ ) result in quick establishment of steady-state fractionation, which-in contrast to the case of diffusive growth-is far from zero for the two values of $R \cdot x_{\mathrm{BL}} / D$ explored in the figure. See Fig. 7 for outcomes involving other $R \cdot x_{\mathrm{BL}} / D$ values 


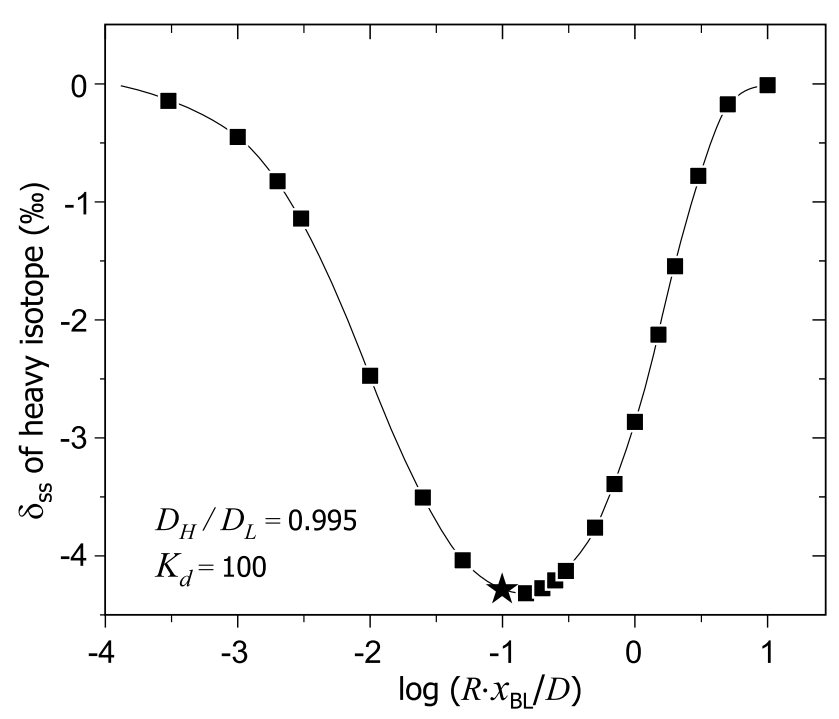

Fig. 7 Steady-state fractionation $\delta_{\mathrm{ss}}$ during convective bubble growth as a function of $\log \left(R \cdot x_{\mathrm{BL}} / D\right)$ at $K_{\mathrm{d}}=100$ and $D_{\mathrm{H}} / D_{\mathrm{L}}=0.995$. Note that the "optimal" value of $R \cdot x_{\mathrm{BL}} / D$-i.e., that yielding maximum fractionation-is close to 0.1 . High $R \cdot x_{\mathrm{BL}} / D$ values $(>10)$ produce no fractionation because fast growth allows for little or no diffusion; low $R \cdot x_{\mathrm{BL}} / D$ values $(<0.0001)$ produce no fractionation because slow growth allows diffusion to maintain equilibrium

other hand, diffusion is fast enough to maintain partitioning equilibrium for both the slow and fast diffusants, so little or no fractionation occurs between the bubble and the melt.

The shape of the curve in Fig. 7 raises questions as to its generality, so additional simulations were conducted using other input values of $D_{\mathrm{H}} / D_{\mathrm{L}}$ and $K_{\mathrm{d}}$. Figure 8 explores the effect of varying $D_{\mathrm{H}} / D_{\mathrm{L}}$ at the maximum fractionation $R \cdot x_{\mathrm{BL}} / D$ value of 0.1 . The left panel illustrates the rapid approach to steady-state fractionation; the right panel shows that the magnitude of the steady-state fractionation depends linearly on $D_{\mathrm{H}} / D_{\mathrm{L}}$. As is clear from Fig. 9, the linear relationship between $\delta_{\mathrm{ss}}$ and $D_{\mathrm{H}} / D_{\mathrm{L}}$ carries over to all relevant values of the bubble/melt partition coefficient $K_{\mathrm{d}}$, although the slopes vary in a systematic manner. This graph also reinforces the point made in "Passive volatiles" that essentially the same diffusive fractionation is produced by any value of $K_{\mathrm{d}}$ exceeding $\sim 100$.

The remaining question about Fig. 7 is whether the dependence of the steady-state fractionation value $\delta_{\mathrm{ss}}$ on $R \cdot x_{\mathrm{BL}} / D$ can be generalized in some way to other values of $D_{\mathrm{H}} / D_{\mathrm{L}}$. The answer is shown in Fig. 10, where the curve from Fig. 7 is reproduced with an expanded vertical scale to accommodate similar curves for two additional values of $D_{\mathrm{H}} / D_{\mathrm{L}}$. The curves for $D_{\mathrm{H}} / D_{\mathrm{L}}=0.975$ and 0.95 are shown only as thin lines, but each was determined from numerical simulations run at the same $20 R \cdot x_{\mathrm{BL}} / D$ values for which data points are shown in the top curve. The three curves differ only by vertical stretching or compression in linear proportion to the difference in $D_{\mathrm{H}} / D_{\mathrm{L}}$.

As just noted, the magnitude of bubble/melt fractionation by diffusion during convective bubble growth is captured by a single curve like that shown in Figs. 7 and 10, but the curve is stretched or compressed vertically depending on the values of $D_{\mathrm{H}} / D_{\mathrm{L}}$ and $K_{\mathrm{d}}$. An efficient way to quantify the $\delta_{\mathrm{ss}}$ axis without using a large number of graphs is to develop an equation that describes the location of the $\delta_{\mathrm{ss}}$ minimum as a function of $D_{\mathrm{H}} / D_{\mathrm{L}}$ and $K_{\mathrm{d}}$. The minimum is close to $R \cdot x_{\mathrm{BL}} / D=0.1$, so this value was used as a convenient round number. For clarity, steady-state fractionation at $R \cdot x_{\mathrm{BL}} / D=0.1$ is designated by the symbol $\delta_{\mathrm{ss}(0.1)}$, which is a linear function of $D_{\mathrm{H}} / D_{\mathrm{L}}$ (Fig. 9). In fact, all lines in Fig. 9 conform to the simple relationship

$\delta_{\mathrm{ss}(0.1)}=B \cdot\left(D_{\mathrm{H}} / D_{\mathrm{L}}-1\right)$,

where $B$ is a constant. For $\log K_{\mathrm{d}}$ ranging from 1 to 3 , the value of $B$ depends in non-linear fashion on $\log K_{\mathrm{d}}$ :

$$
\begin{aligned}
B= & -630.5+1512 \cdot \log K_{\mathrm{d}}-490 \cdot\left(\log K_{\mathrm{d}}\right)^{2} \\
& +53.5 \cdot\left(\log K_{\mathrm{d}}\right)^{3}
\end{aligned}
$$

For $\log K_{\mathrm{d}} \geq 3, B=940$. Steady-state fractionation at $R \cdot x_{\mathrm{BL}} / D=0.1$ is readily calculated from Eqs. 12 and 13, and estimates for other values of $R \cdot x_{\mathrm{BL}} / D$ can be obtained
Fig. 8 Left panel evolution of $\delta_{\mathrm{H}}$ in the bubble for convectivegrowth scenarios involving differences in $D_{\mathrm{H}} / D_{\mathrm{L}}$ at the maximum fractionation $R \cdot x_{\mathrm{BL}} / D$ value of 0.1 (when a steady state is reached, this maximum fractionation is designated as $\left.\delta_{\mathrm{ss}(0.1)}\right)$. The magnitude of $\delta_{\mathrm{ss}(0.1)}$ depends linearly upon $D_{\mathrm{H}} / D_{\mathrm{L}}$ (right panel). See text for discussion
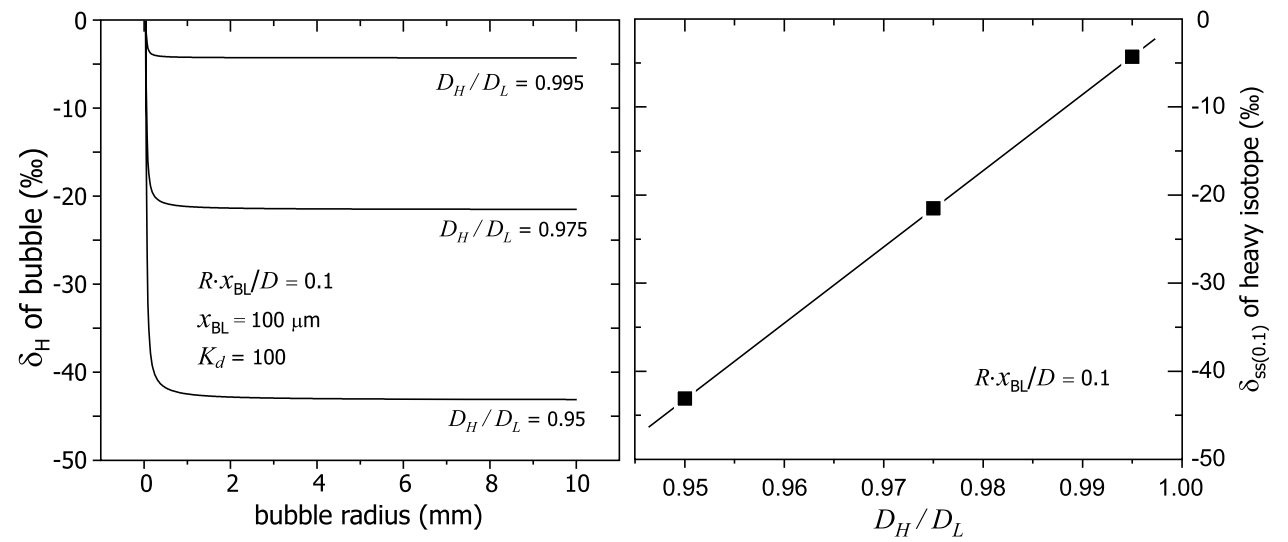


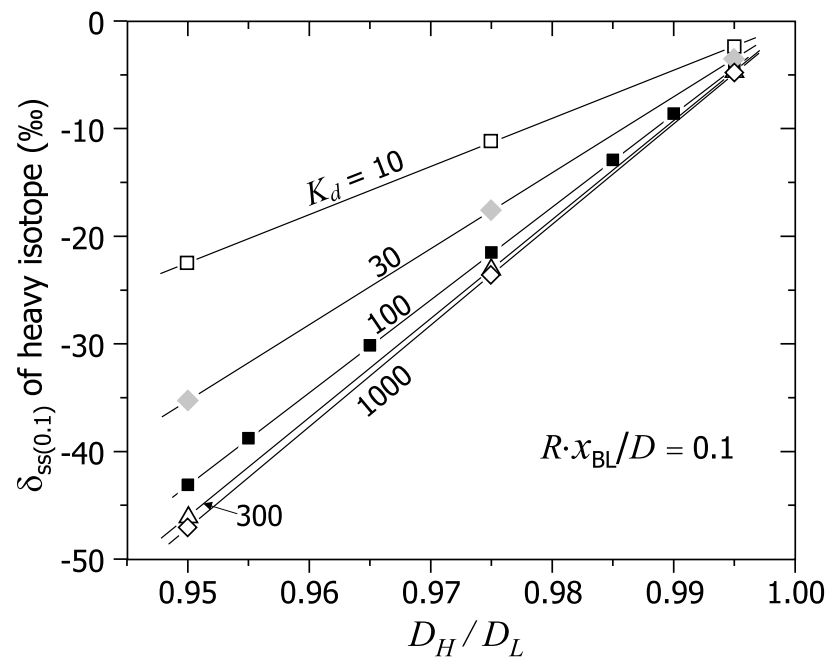

Fig. 9 Plot showing linear dependencies of $\delta_{\mathrm{ss}(0.1)}$ upon $D_{\mathrm{H}} / D_{\mathrm{L}}$ for a range of $K_{\mathrm{d}}$ values at $R \cdot x_{\mathrm{BL}} / D=0.1$. Note that differences in slope become very minor for $K_{\mathrm{d}}$ greater than $\sim 100$. Similar lines with shallower slopes apply to other values of $R \cdot x_{\mathrm{BL}} / D$ (see text and Eqs. 7-9)

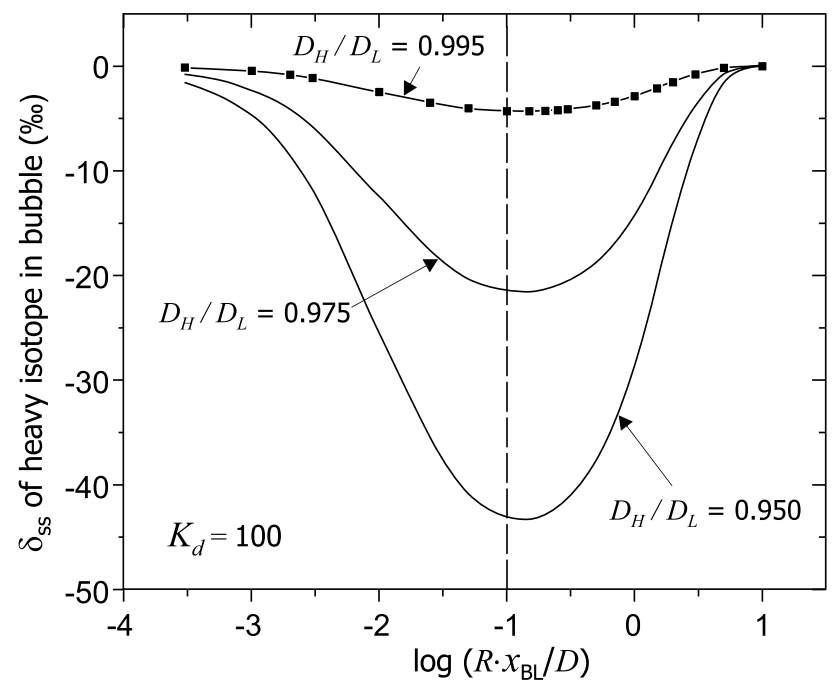

Fig. 10 Plot similar to Fig. 7 but showing steady-state fractionation during convective bubble growth for three values of $D_{\mathrm{H}} / D_{\mathrm{L}}$. The top curve for $D_{\mathrm{H}} / D_{\mathrm{L}}=0.995$ is the same as Fig. 7; the middle and lower curves are for $D_{\mathrm{H}} / D_{\mathrm{L}}=0.975$ and 0.950 , respectively. The black squares along the top curve indicate to 20 values of $R \cdot x_{\mathrm{BL}} / D$ where $\delta_{\mathrm{ss}}$ was numerically computed; the same 20 values were used to define $\delta_{\mathrm{ss}}$ as a function of $\log \left(R \cdot x_{\mathrm{BL}} / D\right)$ for $D_{\mathrm{H}} / D_{\mathrm{L}}=0.975$ and 0.950

by rescaling the vertical axis on Fig. 7. For highly volatile components $\left(K_{\mathrm{d}} \geq 1000\right)$, the maximum diffusive fractionation of isotopes during convective bubble growth (at $R \cdot x_{\mathrm{BL}} / D \cong 0.1$ ) is given simply by

$\delta_{\mathrm{ss}(0.1)}=940 \cdot\left(D_{\mathrm{H}} / D_{\mathrm{L}}-1\right)$,

In applying the above equations to a real-world situation, it is important to bear in mind that they provide estimates of the magnitude of steady-state isotopic fractionation specifically. Interestingly, the extent and duration of bubble growth required to establish a steady state depends upon the boundary layer width $x_{\mathrm{BL}}$ (Fig. 6), so there is a link between the physical dynamics of the system (which determines $x_{\mathrm{BL}}$ ) and the onset of steady-state diffusive fractionation of isotopes in exsolved bubbles: bubble motion in magma $\rightarrow$ thin boundary layer $\rightarrow$ rapid establishment of steady state $(\rightarrow$ predictable diffusive fractionation).

It was noted in "General approach" that Eq. 7 has been applied to the case of convective bubble growth just described. This equation is adequate as a description of the instantaneous rate of convective bubble growth (in terms of the diffusive flux of molecules through the bubble/melt interface), but it cannot be integrated to obtain time-averaged effects without knowledge of the dependencies of the bubble radius $\left(r_{\mathrm{b}}\right)$ and volatile solubility $\left(C_{\mathrm{sat}}\right)$ upon time (and, in general, it is knowledge of $r_{\mathrm{b}}=f(t)$ that is sought). Other limitations of Eq. 7 include the facts that: it is one-dimensional (it is essentially the steady-state diffusion equation in one dimension); it assumes that the concentration gradient across the boundary layer is linear (in spherical coordinates, the gradient is not linear even when a steady-state is achieved); it does not capture growth by simple expansion; and it does not consider the time interval during bubble growth when diffusion effects have not reached the outer perimeter of the physical boundary layer (i.e., it implies that steady-state growth is established instantaneously). Depending on circumstances, this last limitation may or may not be important. The overall shortcomings aside, Eq. 7 can be integrated in step-wise fashion, allowing $r_{\mathrm{b}}, C_{\mathrm{sat}}$ and $x_{\mathrm{BL}}$ to change with successive time steps (Fortin et al. 2016). This strategy was used by Bottinga and Javoy (1990a) in implementing an equation similar to Eq. 7.

Before closing this section on general convective bubble growth, it is worth noting that the linear relationship between $D_{\mathrm{H}} / D_{\mathrm{L}}$ and $\delta_{\mathrm{ss}(0.1)}$ for isotopes (Figs. 8, 9) also holds quite well for separate volatiles whose diffusivities differ markedly (i.e., $D_{\text {slow }} / D_{\text {fast }} \ll 1$; see Fig. 11 ). As previously noted, however, diffusive fractionation of volatiles during bubble growth in natural systems may be difficult to isolate in the presence of expected equilibrium fractionation.

\section{Active volatiles: $\mathrm{CO}_{2}$ and $\mathrm{H}_{2} \mathrm{O}$}

\section{Exsolution of $\mathrm{CO}_{2}$ from MORB}

In this section, models are briefly described in which diffusive- and convective growth of $\mathrm{CO}_{2}$ bubbles in basaltic melt is explicitly calculated, along with 


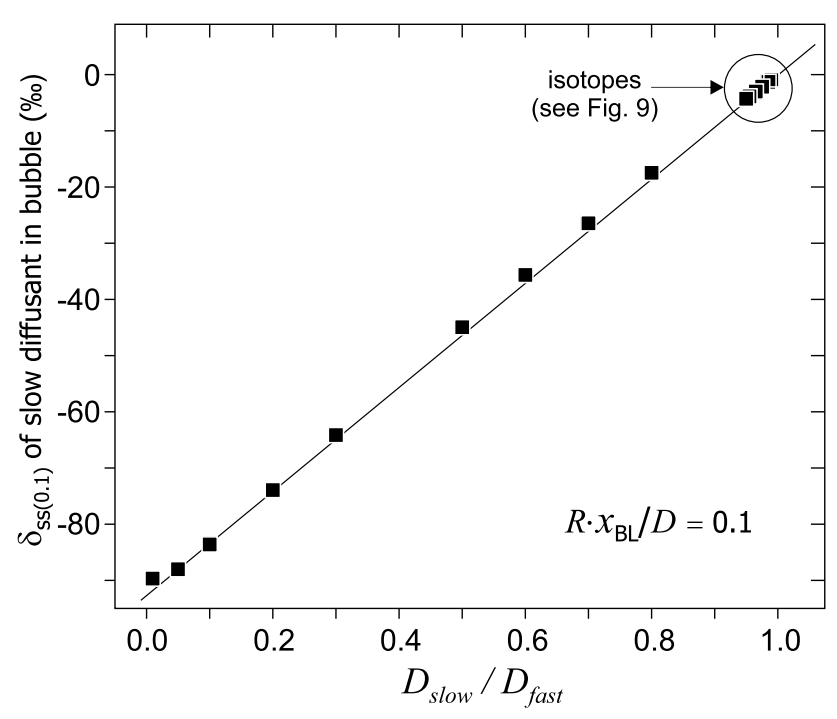

Fig. 11 Steady-state fractionation $\left(\delta_{\mathrm{ss}(0.1)}\right)$ during convective bubble growth at $R \cdot x_{\mathrm{BL}} / D=0.1$ for $D_{\text {slow }} / D_{\text {fast }}$ spanning two orders of magnitude. As in Fig. 4, the upper right extreme of the plot is relevant to isotopes

accompanying diffusive fractionations. In contrast to models described in previous sections, the growth rate of the bubble is not an input parameter here but an outcome of the model. Carbon dioxide is generally present in MORB basalts at a level of several hundred ppm (e.g., Johnson et al. 1994), and because the solubility of $\mathrm{CO}_{2}$ in basalt is limited and steeply pressure-dependent (e.g., Blank and Brooker 1994; Newman and Lowenstern 2002), MORB magmas will tend to reach saturation in $\mathrm{CO}_{2}$-rich vapor at some stage in their decompression history (although this does not automatically lead to instantaneous bubble nucleation; Aubaud et al. 2004; Bottinga and Javoy 1990b; Gonnermann and Manga 2005; 2007). Passive volatiles (which include $\mathrm{H}_{2} \mathrm{O}$ in this case) are partitioned between the growing, $\mathrm{CO}_{2}$-dominated bubbles and melt. Possible diffusive fractionations in this scenario include not only those involving the isotopologues of $\mathrm{CO}_{2}$ itself but also the isotopes of all other (passive) volatiles, and the individual volatiles from one another. No measurements have been made to date on the isotope mass effect on $\mathrm{CO}_{2}$ (or $\mathrm{CO}_{3}^{2-}$ ) diffusion in silicate melts, so models of diffusive fractionation of $\mathrm{C}$ species during $\mathrm{CO}_{2}$ bubble growth are purely illustrative at this point. Even though the present models are not intended to capture the behavior of any specific system, the insight they provide into the time dependence of $\mathrm{d} r_{\mathrm{b}} / \mathrm{d} t$ during diffusive and convective growth is potentially valuable (up to this point in this study, $\mathrm{d} r_{\mathrm{b}} / \mathrm{d} t$ has been assumed to be constant).

\section{Diffusive growth of $\mathrm{CO}_{2}$ bubbles in basalt}

The models assume an initial magmatic $\mathrm{CO}_{2}$ content of $500 \mathrm{ppm}$, which would result in bubble formation at $\sim 1100$ bars during decompression at $\sim 1200{ }^{\circ} \mathrm{C}$ (Newman and Lowenstern 2002) if the interfacial energy barrier to nucleation is ignored (this is relatively small in mafic systems; Gonnermann and Manga 2007). Accordingly, the model system starts out at 1100 bars and decompresses at preset rates of $0.01,0.001$, and $0.0001 \mathrm{bars} / \mathrm{s}$ down to 100 bars. Bubble nucleation is assumed to occur instantaneously, and growth progresses as a consequence of both PVT expansion and diffusion of $\mathrm{CO}_{2}$ into the bubble (see "Equations of state, diffusion laws and solubilities" for EOS and diffusion sources; note, again, that in real systems the volatile phase would not be pure $\mathrm{CO}_{2}$ ). The temperature is held constant at $1200{ }^{\circ} \mathrm{C}$ throughout the simulation; the $\mathrm{H}_{2} \mathrm{O}$ content of the melt is assumed to be $0.4 \mathrm{wt} \%$ (this affects the diffusivity of $\mathrm{CO}_{2}$; Zhang and Ni 2010).

Figure 12 shows results for diffusive growth of $\mathrm{CO}_{2}$-rich bubbles given the conditions just described. Graphs of $R$ vs. time (Fig. 12a, b) and $r_{b}$ vs. time (Fig. 12c) reveal highly non-linear growth behavior for all three decompression rates, which is not unexpected in view of the nearly 10 -fold decrease in $\mathrm{CO}_{2}$ density over the 1000-bar drop in pressure $\left(\rho_{\mathrm{m}}\right.$ drops from 0.319 to $0.035 \mathrm{~g} / \mathrm{cm}^{3}$ ). Interestingly, despite the difference in bubble size at the end of the three decompression paths, the final $\delta_{\mathrm{H}}$ in the bubble is the same: $-3.53 \%$ o for an assumed heavy/light diffusivity ratio $D_{\mathrm{H}} / D_{\mathrm{L}}$ of 0.995 (Fig. 12d). This diagram is made much more useful by the fact that the final $\delta_{\mathrm{H}}$ in the bubble scales linearly with $D_{\mathrm{H}} / D_{\mathrm{L}}$ [see Fig. $12 \mathrm{e} ; \delta_{\mathrm{H}}=714 \times\left(D_{\mathrm{H}} / D_{\mathrm{L}}-1\right)$ ] and does not depend on growth rate. If the isotope (isotopologue) mass effect on $\mathrm{CO}_{2}$ diffusion is measured in future experiments and $D_{\mathrm{H}} / D_{\mathrm{L}}$ differs from the value of 0.995 used here, Fig. 12 will not be made instantly obsolete.

A remaining question about diffusive growth of $\mathrm{CO}_{2}$ bubbles is the width of the diffusion field in the melt around the growing bubble. This could be roughly estimated as $\sqrt{2 D t}$, but a more accurate depiction, including evolution with time, is provided in Fig. 12f. The set of curves in this figure applies specifically to the fastdecompression scenario $(\mathrm{d} P / \mathrm{d} t=-0.01 \mathrm{bars} / \mathrm{s})$, which results in the narrowest diffusion zone. Even in this case, however, the diffusion field is several hundred microns wide at the end of the decompression path. Most of the change in isotope ratio in the melt takes place within $\sim 100$ microns of the bubble interface, but it is nevertheless clear that convective bubble growth scenarios-in which diffusion is confined to a physically limited boundary layer-must also be considered. 
Fig. 12 Diffusive growth models for $\mathrm{CO}_{2}$-rich bubbles in basaltic melt decompressing isothermally at $1200{ }^{\circ} \mathrm{C}$. a Growth rate as a function of time for decompression at 0.001 bars/s. b Similar plot to (a) but using a $\log (t)$ scale to compare bubble growth at three different decompression rates (indicated on figure). $\mathbf{c} \mathrm{CO}_{2}$ bubble radius as a function of time for the same three decompression rates. d $\delta_{\mathrm{H}}(\% o)$ in the bubble as a function of bubble radius for the specific case of $D_{H} / D_{L}=0.995$. (e) Linear dependence of the final $\delta_{\mathrm{H}}$ in the bubble upon $D_{\mathrm{H}} / D_{\mathrm{L}}$ over the full range of plausible values for isotopes. $\mathbf{f}$ Ten "snapshots" of $\delta_{\mathrm{H}}$ profiles in the melt against the advancing bubble/melt interface for decompression at $0.01 \mathrm{bars} / \mathrm{s}$ when $D_{\mathrm{H}} / D_{\mathrm{L}} 0.995$ (note that the center of the $\mathrm{CO}_{2}$ bubble is at zero on the distance axis). See text for details and discussion
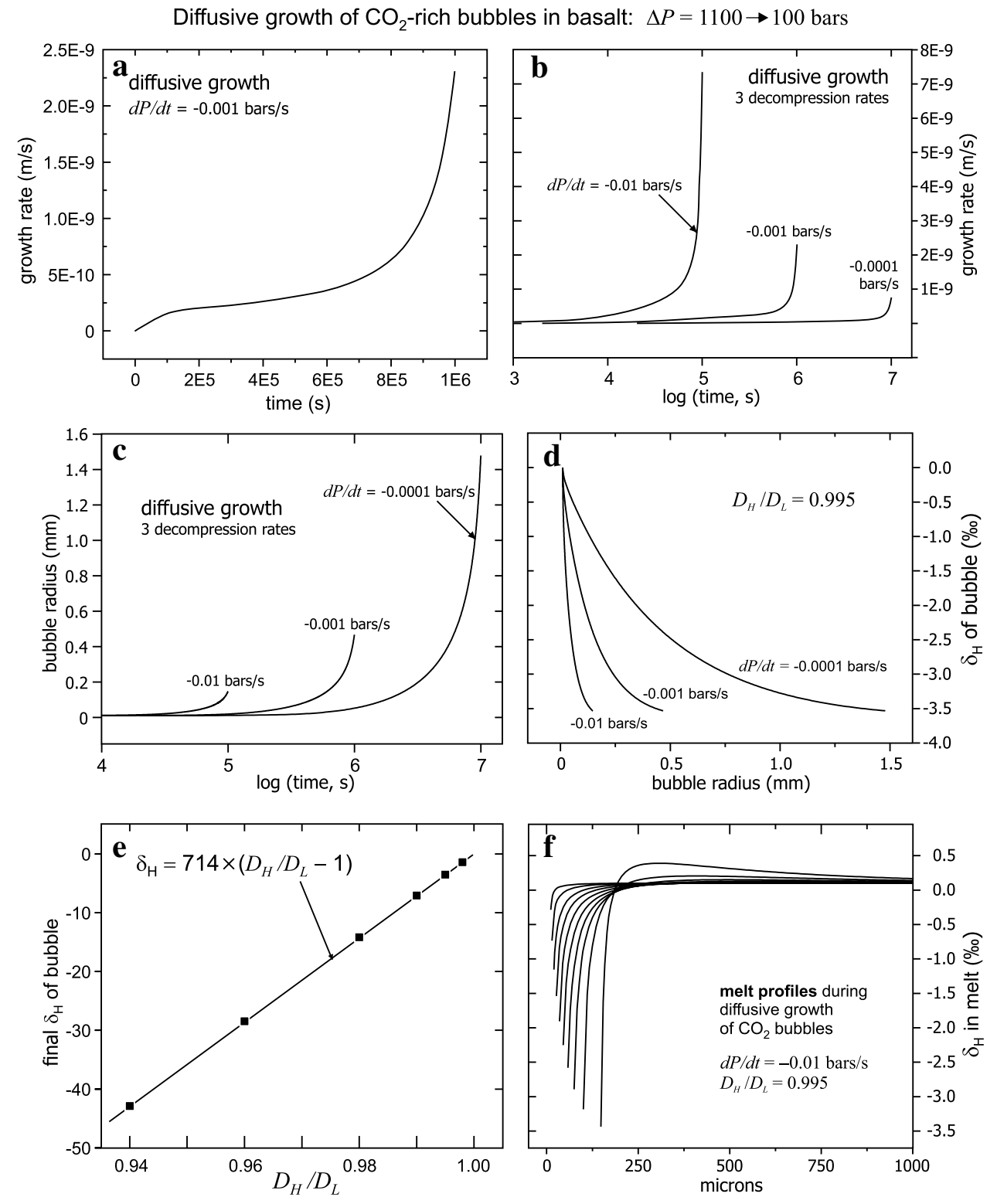

Convective growth of $\mathrm{CO}_{2}$ bubbles in basalt

Convective growth of $\mathrm{CO}_{2}$-rich bubbles in basaltic melt was explored using the same decompression paths described in the previous section- $\mathrm{d} P / \mathrm{d} t=-0.01$, -0.001 and -0.0001 bars/s-with the boundary layer width $x_{\mathrm{BL}}$ ranging from 30 to 100 microns (which is appropriate for the inviscid basaltic melt under consideration; see "Convective bubble growth (dynamic system)"). Growth behavior is illustrated for the specific case of $x_{\mathrm{BL}}=30 \mu \mathrm{m}$ in Fig. 13a, where growth rate $R$ is plotted against $\log (t)$ to show the three decompression scenarios on a single graph. In Fig. 13b, a linear time axis is used to more clearly show the exponentially increasing growth rate for the specific case of $\mathrm{d} P / \mathrm{d} t=-0.001$ bars/s. Figure $13 \mathrm{~b}$ includes $R$ vs. $t$ curves for two values of $x_{\mathrm{BL}}$ (30 and $\left.100 \mu \mathrm{m}\right)$ and also for purely diffusioncontrolled growth (from Fig. 12a). From this comparison it is clear that the presence of a narrow boundary layer results in a significantly enhanced rate of bubble growth. It is also apparent that, as expected, convective growth behavior migrates toward the pure-diffusion case as $x_{\mathrm{BL}}$ increases. Figure 13c illustrates the effect of varying $x_{\mathrm{BL}}$ on the final radii of bubbles produced along the three decompression paths. As in the case of diffusive growth, small bubbles result from fast decompression: a tenfold increase in decompression rate leads to roughly a tenfold reduction in final bubble size. Also, as in the case of diffusive growth, however, the rate of decompression has little or no effect on the amount of isotopic fractionation observed in the final bubble (Fig. 13d). Moreover, the value of $\delta_{\mathrm{H}}$ in the bubble at the completion of the 
Fig. 13 Series of plots similar to those shown in Fig. 12, but in this case for convective growth of $\mathrm{CO}_{2}$ bubbles in basalt decompressing isothermally at $1200{ }^{\circ} \mathbf{C}$. a-b Bubble growth rate vs. time curves (simulation details are on the diagrams). c Dependence of $\mathrm{CO}_{2}$ bubble radius on boundary-layer width $x_{\mathrm{BL}}$ and decompression rate. $\mathbf{d} \delta_{\mathrm{H}}$ in the bubble for growth at three decompression rates when $D_{\mathrm{H}} / D_{\mathrm{L}}=0.995$ and $x_{\mathrm{BL}}=30 \mu \mathrm{m}$. e Linear dependence of the final $\delta_{\mathrm{H}}$ in the bubble upon $D_{\mathrm{H}} / D_{\mathrm{L}}$ for $x_{\mathrm{BL}}=30 \mu \mathrm{m}$ and $100 \mu \mathrm{m}$. $\mathbf{f}$ Ten "snapshots" of $\delta_{\mathrm{H}}$ profiles across a $30-\mu \mathrm{m}$ wide boundary layer against the advancing bubble/melt interface for decompression at $0.01 \mathrm{bars} / \mathrm{s}$ when $D_{\mathrm{H}} / D_{\mathrm{L}} 0.995$ (note that the center of the $\mathrm{CO}_{2}$ bubble is at zero on the distance axis). See text for discussion
Convective growth of $\mathrm{CO}_{2}$-rich bubbles in basalt: $\Delta P=1100 \rightarrow 100$ bars
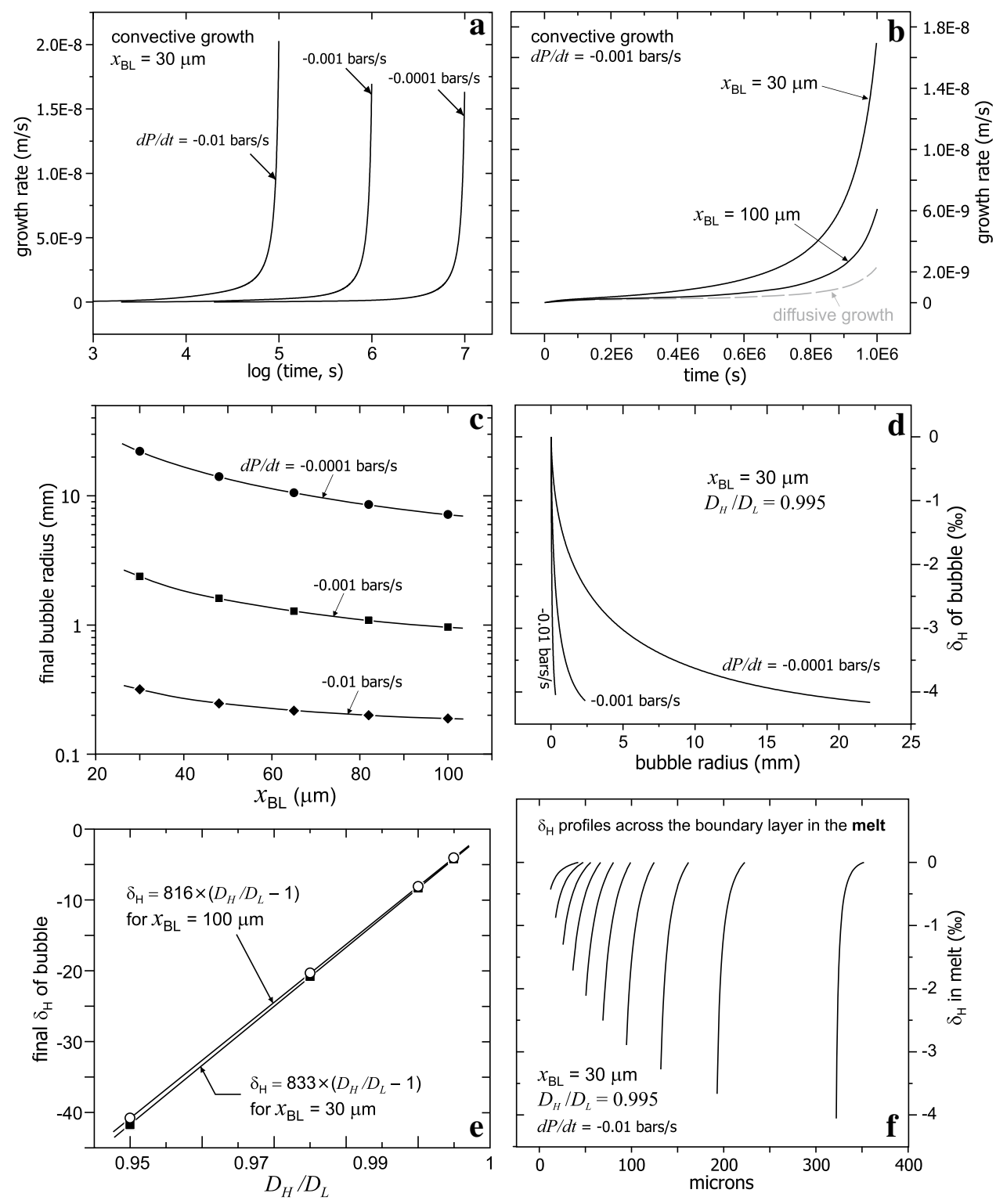

"convective" decompression paths is only $~ 15 \%$ more negative than the pure-diffusion case. The final value of $\delta_{\mathrm{H}}$ in the bubble depends on $D_{\mathrm{H}} / D_{\mathrm{L}}$, but the dependence is linear over the range in $D_{\mathrm{H}} / D_{\mathrm{L}}$ relevant to isotopes, and very insensitive to the width of the boundary layer (Fig. 13e).

Figure $13 \mathrm{f}$ shows the evolution with time of the $\delta_{\mathrm{H}}$ profile across a $30-\mu \mathrm{m}$ wide boundary layer in the melt for the fastest decompression path $(\mathrm{d} P / \mathrm{d} t=-0.01$ bars/s). As in Fig. 12f, the ten curves are separate "snapshots" of the boundary layer at successive stages in the growth of the bubble, the center of which is at zero on the horizontal axis.

\section{Natural scenarios involving passive volatiles}

\section{Fractionation of noble gases during growth of $\mathrm{CO}_{2}$ bubbles}

Given the computed growth behavior of $\mathrm{CO}_{2}$-rich bubbles reported in the previous section, it may be of interest to explore the possible fractionation of passive volatiles such as the noble gases during growth of these bubbles, focusing in this instance upon separation of one volatile from another rather than isotopes or isotopologues of a single volatile. Evidence of kinetic fractionation of noble gases during bubble growth has been noted in mafic 
volcanics (e.g., Gonnermann and Mukhopadhyay 2007; Paonita and Martelli 2007; Burnard et al. 2003), and a detailed study by Aubaud et al. (2004) revealed that high degrees of supersaturation of basaltic melt with respect to $\mathrm{CO}_{2}$ lead to elevated $\mathrm{He} / \mathrm{Ar}$ ratios in quenched bubbles. This observation may indicate that high growth rates accompanying $\mathrm{CO}_{2}$ supersaturation can lead to enrichment of fast-diffusing $\mathrm{He}$ in the bubbles.

For the present illustrative models, the diffusivities of noble gases were assumed to be: $\mathrm{He}-5 \times 10^{-9} \mathrm{~m}^{2} / \mathrm{s}$; $\mathrm{Ar}$ $-6 \times 10^{-10} \mathrm{~m}^{2} / \mathrm{s} ; \mathrm{Xe}-3 \times 10^{-10} \mathrm{~m}^{2} / \mathrm{s}$. These values are based on the experimental determinations of Lux (1987) at $1350{ }^{\circ} \mathrm{C}$, which is significantly hotter than the $1200{ }^{\circ} \mathrm{C}$ assumed for the present model (see previous section). However, it is the relative diffusivities of the noble gases that are most important for the present comparison, and only Lux (1987) has measured the diffusivities of all noble gases using internally consistent methods. Moreover, the value of Lux (1987) for He is close to that used by Aubaud et al. (2004), which was based on the measurements of Kurz and Jenkins (1981). The growth rate vs. time relationship for noble-gas bearing $\mathrm{CO}_{2}$ bubbles was taken from Fig. 13b, specifically for $x_{\mathrm{BL}}=30 \mu \mathrm{m}$ and $\mathrm{d} P / \mathrm{d} t=-0.001$ bars/s (decompression from 1100 to 100 bars). To simplify the diffusion calculations for the noble gases, the growth-rate curve ( $R$ vs. $t$ ) was approximated as a simple exponential as shown in Fig. 14a.
In models of diffusive isotope fractionation discussed previously, equilibrium isotopic fractionation was assumed to be negligible at the high temperatures relevant to bubble growth. Fractionation of noble gases from one another is a different matter, however, because equilibrium fractionation is likely to be substantial. To assess the magnitude of diffusion effects, a reasonable approach is to compare noble-gas fractionation during bubble growth with and without including differences in their diffusivities. As noted in "General approach", the partitioning of noble gases between vapor and melt is generally represented by the Henry's law constant $K_{\mathrm{H}}=C_{\mathrm{m}} / p_{\mathrm{i}}$, where $p_{\mathrm{i}}$ is the partial pressure of the gas of interest in the vapor (Lux 1987; Ozima and Podosek 2002). Given that $p_{\mathrm{i}} \propto C_{\mathrm{b}} \cdot P$ (where $P=$ total pressure in the bubble), the relationship of $K_{\mathrm{H}}$ to the partition coefficient used previously (Eq. 1) is simply $K_{\mathrm{d}} \propto\left(K_{\mathrm{H}} \cdot P\right)^{-1}$. Use of $K_{\mathrm{H}}$ in modeling noble gas behavior means that vapor/melt partitioning must change during decompression-driven bubble growth, which sets these models apart from those in previous sections. Henry's law constants used in the models for $\mathrm{He}, \mathrm{Ar}$ and Xe were taken from Lux (1987).

The noble-gas fractionation results are shown in Fig. $14 \mathrm{~b}-\mathrm{d}$ as plots of $\mathrm{Ar} / \mathrm{He}, \mathrm{Xe} / \mathrm{Ar}$ and $\mathrm{Xe} / \mathrm{He}$ in the bubble as a function of bubble radius (for the assumed decompression path, the $\mathrm{CO}_{2}$-rich bubble grows to a final radius of $\sim 2.5 \mathrm{~mm}$ ). Each plot includes a curve showing behavior when both elements have the diffusivity of Ar, as well as
Fig. 14 a Convective growth rate vs. time for a $\mathrm{CO}_{2}$ bubble in basalt when $x_{\mathrm{BL}}=30 \mu \mathrm{m}$ and $\mathrm{d} P / \mathrm{d} t=-0.001$ bars $/$ s. Solid curve is numerically computed; dashed curve is an exponential approximation to the computed curve used in the noble gas fractionation calculations illustrated in (b). b-d Model curves showing fractionation of $\mathrm{He}, \mathrm{Ar}$ and $\mathrm{Xe}$ in bubbles produced by the growth curve in (a). Element ratios in the bubbles are shown as a function of bubble radius for two cases: (1) when the diffusivities of the two elements are the same (equal to that of $\mathrm{Ar}$ ); and (2) when the individual diffusivities differ as reported by Lux (1987). Elemental ratios that develop during growth are normalized to an initial equilibrium condition is that given by the Henry's law constants reported in Lux (1987). See text for details and discussion
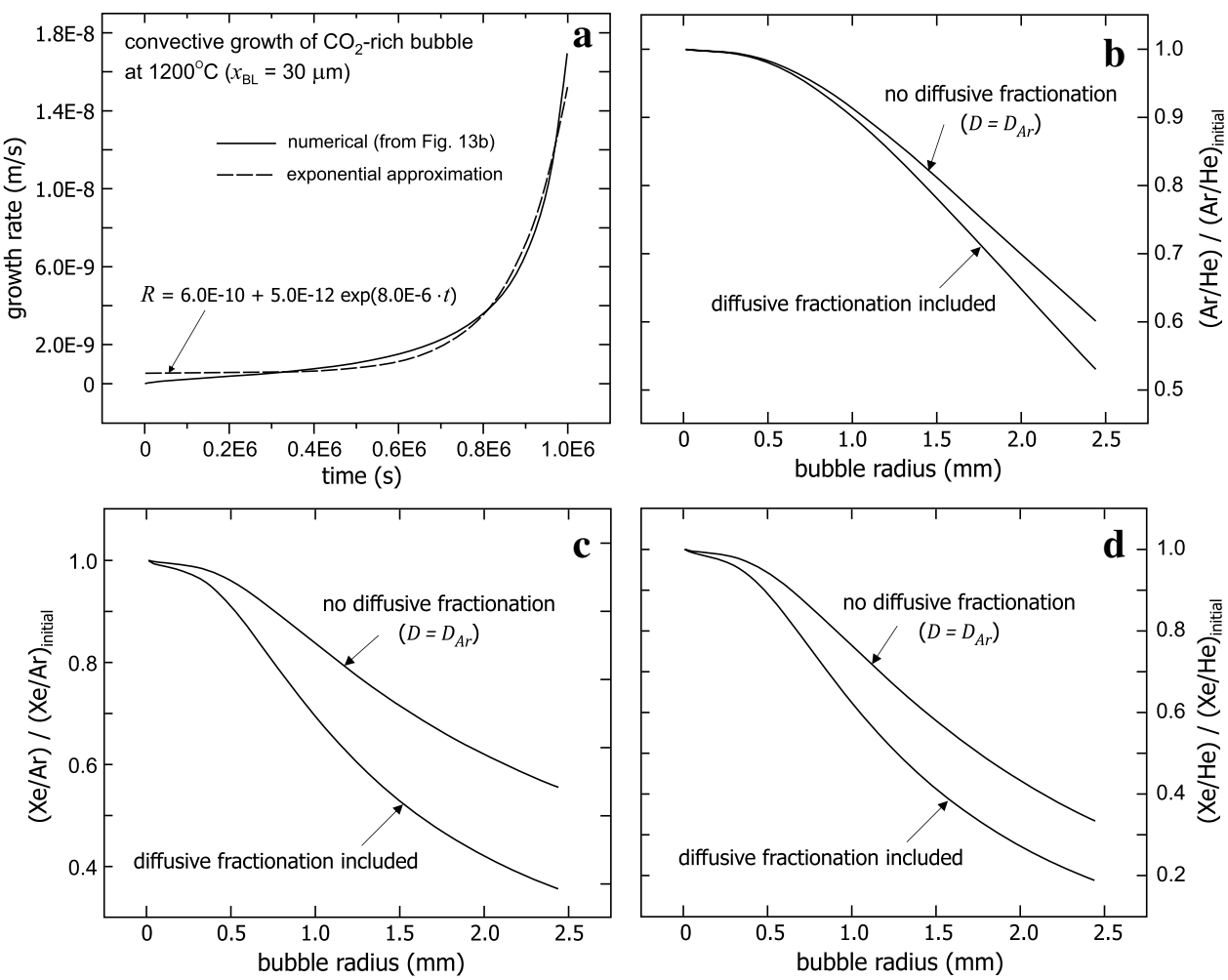
a curve that includes fractionation resulting from the differing $D$ values reported by Lux (1987). For the specific model parameters used, diffusive fractionation effects involving the noble gases are relatively small compared with those caused by partitioning differences. Interestingly, kinetic and equilibrium partitioning effects conspire during decompressive bubble growth to produce substantial changes in element ratios over the "lifetime" of bubbles that attain a large size. Bubbles that do not exceed a millimeter or so in diameter show minimal changes in noble gas ratios relative to the initial equilibrium values. In a broad sense, the model results seem to be consistent with the conclusions of Aubaud et al. (2004) regarding possible kinetic fractionation of noble gases during bubble growth, but it must be cautioned that the magnitude of the separation of noble gases is entirely dependent upon the assumed parameters of the model ( $x_{\mathrm{BL}}$ and decompression path). Additional factors such as delayed nucleation could also play a significant role in determining outcomes, because this would tend to result in faster bubble growth of bubbles once they nucleate.

\section{$\mathrm{Li}$ and $\mathrm{Cl}$ isotopic fractionation during convective growth of $\mathrm{H}_{2} \mathrm{O}$ bubbles in rhyolite}

Although not a magmatic volatile in the traditional (atmophile) sense, $\mathrm{Li}$ is a fluid-mobile species that has been shown to partition into $\mathrm{H}_{2} \mathrm{O}$ vapor relative to rhyolite melt under some conditions (Webster et al. 1989; Vlastélic et al. 2011). The same is true of the more traditional volatile Cl (Webster 1992a, b; Webster et al., 2009). Given the significant difference in diffusivities of ${ }^{6} \mathrm{Li}$ and ${ }^{7} \mathrm{Li}$ in silicate melts (Richter et al. 2003), the potential exists for marked diffusive fractionation of $\mathrm{Li}$ isotopes during growth of $\mathrm{H}_{2} \mathrm{O}$-rich bubbles in rhyolitic magmas. Kinetic fractionation of $\mathrm{Cl}$ isotopes during bubble growth is likely to be more muted than in the case of $\mathrm{Li}$, but potentially significant nevertheless. Comparison of $\mathrm{Li}$ and $\mathrm{Cl}$ makes an interesting study in contrasts because $\mathrm{Li}$ is a fast diffuser exhibiting a large isotope mass effect, and $\mathrm{Cl}$ is a slow diffuser with a modest isotope mass effect. In terms of $P-T$ conditions and paths, the modeling possibilities for bubble exsolution from rhyolite melt are innumerable; the example here should be regarded as purely illustrative and not intended to represent any specific natural system. The goal of the model is to evaluate the possible magnitudes of diffusive fractionation of $\mathrm{Li}$ and $\mathrm{Cl}$ isotopes during growth of $\mathrm{H}_{2} \mathrm{O}$-rich bubbles in rhyolite melt when the growth rate of the bubble is determined solely by $\mathrm{H}_{2} \mathrm{O}$ diffusion and bubble expansion accompanying decompression. As in the basalt $/ \mathrm{CO}_{2}$ case just discussed, other factors affecting bubble growth are not considered here, but the choice of a convective growth model incorporating a relatively narrow physical boundary layer $\left(x_{\mathrm{BL}}=100 \mu \mathrm{m}\right)$ implies a vigorous system. The model system is assumed to decompress isothermally (at $750{ }^{\circ} \mathrm{C}$ ) from 1000 to 500 bars at 0.009 bars/s, during which the density of $\mathrm{H}_{2} \mathrm{O}$ vapor drops from $\sim 0.25$ to $\sim 0.12 \mathrm{~g} / \mathrm{cm}^{3}$ (Halbach and Chatterjee 1982) and the solubility in the melt from $\sim 4.2$ to $\sim 2.8 \mathrm{wt} \%$ (Newman and Lowenstern 2002). The numerical algorithm is complicated by the fact that the diffusivity of $\mathrm{H}_{2} \mathrm{O}$ in rhyolite depends strongly upon dissolved $\mathrm{H}_{2} \mathrm{O}$ content (Zhang and $\mathrm{Ni} 2010$ ), so $\mathrm{D}_{\mathrm{H} 2 \mathrm{O}}$ must be recalculated at every node point for each time step.

Figure $15 \mathrm{a}, \mathrm{b}$ illustrate convective growth of an $\mathrm{H}_{2} \mathrm{O}$ bubble for the conditions described above, up to a final radius of $2.5 \mathrm{~mm}$. As in the case of $\mathrm{CO}_{2}$ bubble growth in basalt, the $R$ vs. $t$ curve for $\mathrm{H}_{2} \mathrm{O}$ bubble growth in rhyolite is exponential in form (Fig. 15b). The overall shape of the computed growth curve (Fig. 15a) resembles the experimental determinations of Liu and Zhang (2000) for hydrous rhyolite, but the details differ because of the mismatch in temperature and decompression path, and also because of the simplistic nature of the present model.

Modeling $\mathrm{Li}$ and $\mathrm{Cl}$ isotope fractionation during $\mathrm{H}_{2} \mathrm{O}$ bubble growth requires knowledge of elemental diffusivities and isotope mass effects that is incomplete at present-although plausible estimates are possible. The diffusivity of $\mathrm{Li}$ in wet rhyolite is assumed to be $1.0 \times 10^{-10}$ $\mathrm{m}^{2} / \mathrm{s}$ - a value based not upon actual measurements, but upon the fact that $\mathrm{D}_{\mathrm{Li}} \approx \mathrm{D}_{\mathrm{Na}}$ in silicic melts (Zhang et al. 2010), combined with the observation of Watson (1981) that for cations whose diffusivities are fast in dry rhyolite melt (such as $\mathrm{Na}^{+}$), the increase in diffusivity with added $\mathrm{H}_{2} \mathrm{O}$ is very modest. The diffusivity of $\mathrm{Cl}$ in wet rhyolite is taken as $1.0 \times 10^{-12} \mathrm{~m}^{2} / \mathrm{s}$, based on the studies of Watson (1991) and Bai and Koster van Groos (1994). Chlorine diffusion in wet rhyolite depends on the $\mathrm{H}_{2} \mathrm{O}$ content of the melt, but this dependence has not been characterized in detail at $750{ }^{\circ} \mathrm{C}$. However, the effect of $\mathrm{H}_{2} \mathrm{O}$ is modest in the $2-4 \mathrm{wt} \% \mathrm{H}_{2} \mathrm{O}$ range at $850{ }^{\circ} \mathrm{C}$ (Bai and Koster van Groos (1994), so use of a best-guess average value for $\mathrm{D}_{\mathrm{Cl}}$ is not expected to affect the results in a major way. The isotope mass effect on Li diffusion is assumed to be the same as that measured by Richter et al. (2003) for dry melts at higher temperature $\left(\mathrm{D}_{7 \mathrm{Li}} / \mathrm{D}_{6 \mathrm{Li}}=0.967\right)$, and that for $\mathrm{Cl}$ diffusion is assumed to be the same as that measured by Fortin et al. (2016) for dry dacite melt $\left(\mathrm{D}_{37 \mathrm{Cl}} / \mathrm{D}_{35 \mathrm{Cl}}=0.995\right)$. The bubble/melt partition coefficients for both $\mathrm{Li}$ and $\mathrm{Cl}$ are assumed to be 100 , which is consistent with the studies of Vlastélic et al. (2011) and Webster (1992a,b), and Webster et al. (2009). As in the noble-gas model described previously, the $R$ vs. $t$ curve for $\mathrm{H}_{2} \mathrm{O}$ bubble growth in rhyolite was approximated as a simple exponential relationship (Fig. 15b) to simplify the calculations involving $\mathrm{Li}$ and $\mathrm{Cl}$ isotopes. 
Fig. 15 a Computed radius vs. time curve for an $\mathrm{H}_{2} \mathrm{O}$ bubble growing in molten rhyolite (model conditions are on the figure; see text for additional details). b Growth rate vs. time curve corresponding to the computed curve in (a), with exponential approximation used to compute fractionation of $\mathrm{Li}$ and $\mathrm{Cl}$ isotopes during bubble growth. c, d Fractionation of $\mathrm{Li}$ and $\mathrm{Cl}$ isotopes, respectively, in a growing $\mathrm{H}_{2} \mathrm{O}$ bubble (see panel a), assuming a bubble/ melt $K_{\mathrm{d}}$ of 100 in both cases. The $D_{\mathrm{H}} / D_{\mathrm{L}}$ values for the two elements (shown on the figure) are constrained by experiment in this case. See text for discussion
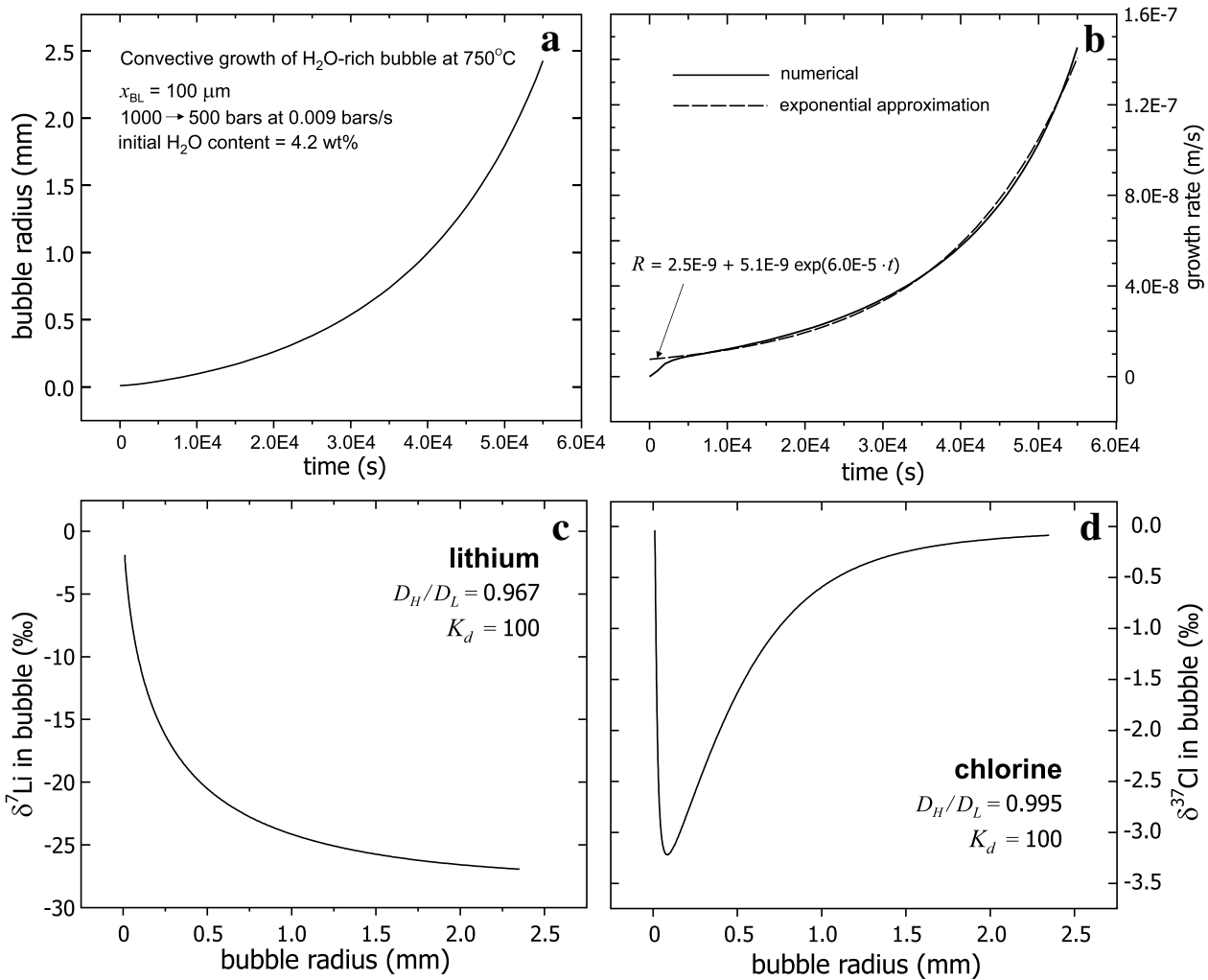

Figure $15 \mathrm{c}, \mathrm{d}$ show the heavy isotope depletions in the bubble for $\mathrm{Li}$ and $\mathrm{Cl}$ relative to the initial melt as a function of bubble radius up to $2.5 \mathrm{~mm}$. The maximum heavy isotope depletion in the bubble is, as expected, much more pronounced for $\mathrm{Li}\left(\delta^{7} \mathrm{Li} \sim-27 \%\right.$ o $)$ than for $\mathrm{Cl}\left(\delta^{37} \mathrm{Cl} \sim-3.5 \%\right.$ o). However, the dependence of heavy-isotope depletion on bubble radius is also very different for the two elements. The maximum ${ }^{37} \mathrm{Cl}$ depletion occurs early in the growth history $\left(r_{\text {bubble }}<100 \mu \mathrm{m}\right)$, whereas ${ }^{7} \mathrm{Li}$ approaches its maximum depletion only after the full $2.5 \mathrm{~mm}$ of bubble growth. Viewed one way, it could be argued that $\mathrm{Cl}$ isotopic fractionation is relatively ephemeral, whereas that of $\mathrm{Li}$ is sustained. Viewed another way, however, the quick minimization of $\delta^{37} \mathrm{Cl}$ in the bubble could increase the likelihood of diffusive fractionation playing a role in natural settings where bubble growth is interrupted early.

\section{Discussion and concluding remarks}

Several broad conclusions can be drawn from the numerical models conducted in this study, the most important of which is that the efficacy of diffusive fractionation of volatiles and their isotopes during bubble growth in melts depends in systematic ways on the interplay between growth rate $(R)$, diffusivity $(D)$ and the diffusivity ratio of the species being compared $\left(D_{\mathrm{H}} / D_{\mathrm{L}}\right.$ in the case of isotopes; $D_{\text {slow }} / D_{\text {fast }}$ in the case of separate volatiles). The volatility, or strength of partitioning into the bubble, also has some influence, but behavior is not very different once the bubble/melt partition coefficient exceeds $\sim 100$. Based on the dynamics of solute redistribution in other moving-boundary systems (e.g., crystal growth), the above generalizations are not surprising (Jambon 1980; Watson and Müller 2009), but the details provided here may expedite application to bubble growth in natural systems. For both diffusive and convective bubble growth, $R / D$ is a key ratio in determining outcomes. For convective growth specifically (where diffusive supply to the bubble occurs through a fixed, fluiddynamically regulated boundary layer), $R / D$ can be combined with the boundary layer width $x_{\mathrm{BL}}$ to obtain a dimensionless number $R \cdot x_{\mathrm{BL}} / D$ that enables generalization to almost any bubble-growth scenario. The potential for diffusive fractionation is greatest when $R \cdot x_{\mathrm{BL}} / D \sim 0.1$, but some fractionation is possible within a range of $R \cdot x_{\mathrm{BL}} / D$ values spanning $\sim 4$ orders of magnitude. The extent of diffusive fractionation within this "window of opportunity" depends linearly upon $D_{\mathrm{H}} / D_{\mathrm{L}}$.

The possibility that diffusive fractionation during bubble growth might lead to a measurable signature (in lavas, glasses, vesicles or exsolved gases) depends entirely on the timing of system decompression, bubble growth and coalescence (and possible resorption), and magma eruption. Generally speaking, geochemical kinetics effects are important to outcomes only if the process or phenomenon of interest is interrupted along the path to equilibrium. In 
the particular case of bubble growth, much will depend upon the time scale of bubble segregation and eruption relative to that of complete diffusive equilibration between bubble and melt. An important conclusion of this study is that, steady-state kinetic fractionation during convective bubble growth is achieved fairly quickly in many cases (see Figs. 6, 8), so in some natural systems there will exist sustained intervals of time over which a kinetic fractionation could persist—which leads to some likelihood that this fractionation might be "sampled" by an eruption. In the interest of full disclosure, a natural system will never attain a true steady state when $R$ is a strong (exponential?) function of time, but substantial diffusive fractionation of isotopes can nevertheless develop quickly and be sustained for a time interval that is long in relation to the overall duration of bubble growth. An interesting case that may illustrate this point is described by de Moor et al. (2013), who called upon diffusive fractionation of ${ }^{32} \mathrm{~S}$ and ${ }^{34} \mathrm{~S}$ to explain the sulfur isotope compositions of gases and scoria at volcanoes in Ethiopia and Nicaragua. It is anticipated that many more such examples will emerge with the expansion of the database on isotopic compositions of volatiles in eruptives and their associated gases. As demonstrated by de Moor et al. (2013), diffusive fractionation during bubble growth can produce effects that are opposite to those expected during equilibrium fractionation.

We note in closing that telltale signs of isotope fractionation during diffusive and convective bubble growth may persist not only in the gas that occupies a vesicle (for example), but also in the quenched glass surrounding that vesicle. This is particularly evident in Fig. 5, which shows $\delta_{\mathrm{H}}$ profiles across a widening diffusive boundary layer against a growing bubble. More subtle but nevertheless characteristic profiles are also produced during convective bubble growth (Fig. 13f). If in situ analytical methods (SIMS in particular) can be implemented to characterize these profiles isotopically, then diffusive fractionation could, in principle, be unequivocally confirmed. In addition, the specific characteristics of the quenched isotopic profile could, through modeling, shed unprecedented light on details of the bubble growth and magma degassing history [a broadly similar approach was used by Castro et al. (2005) in their study of millimeter-scale $\mathrm{H}_{2} \mathrm{O}$ concentration profiles near vesiculation zones; see also Fig. 6 of McIntosh et al. (2014)]. The challenge of interpreting observed isotopic fractionations of volatiles (e.g., de Moor et al. 2013) will be dramatically advanced by detailed knowledge of $D_{\mathrm{H}} / D_{\mathrm{L}}$ in melts for key volatiles, which is obtainable only by experiment. The recent success of Fortin et al. (2016) with chlorine isotopes may bode well for similar studies of other volatiles.
Acknowledgements This work was supported in part by NSF Grant no. EAR-0738843 to EBW. Marc-Antoine Fortin provided valuable input during the conduct of the research. Jim Webster and an anonymous reviewer provided insightful suggestions for improvement of the manuscript.

Open Access This article is distributed under the terms of the Creative Commons Attribution 4.0 International License (http://creativecommons.org/licenses/by/4.0/), which permits unrestricted use, distribution, and reproduction in any medium, provided you give appropriate credit to the original author(s) and the source, provide a link to the Creative Commons license, and indicate if changes were made.

\section{References}

Aubaud C, Pineau F, Jambon A, Javoy M (2004) Kinetic disequilibrium of $\mathrm{C}, \mathrm{He}, \mathrm{Ar}$ and carbon isotopes during degassing of mid-ocean ridge basalts. Earth Planet Sci Lett 222:391-406

Bai TB, Koster van Groos AF (1994) Diffusion of chlorine in granitic magmas. Geochim Cosmochim Acta 58:113-123

Baker LL, Rutherford MJ (1996) Sulfur diffusion in rhyolite melts. Contrib Mineral Petrol 123:335-344

Blank JG, Brooker RA (1994) Experimental studies of carbon dioxide in silicate melts: solubility, speciation, and stable carbon isotope behavior. In: Volatiles in Magmas (MR Carroll and JR Holloway, Eds.), Reviews in Mineralogy v. 30, pp. 157-186, Mineralogical Society of America

Bottinga Y, Javoy M (1989) MORB degassing: evolution of $\mathrm{CO}_{2}$. Earth Planet Sci Lett 95:215-225

Bottinga Y, Javoy M (1990a) MORB degassing: bubble growth and ascent. Chem Geol 81:255-270

Bottinga Y, Javoy M (1990b) Mid-ocean ridge basalt degassing: bubble nucleation. J Geophys Res 95(B4):5125-5131

Bottinga Y, Richet P (1981) High pressure and temperature equation of state and calculation of the thermodynamic properties of gaseous carbon dioxide. Am J Sci 281:615-660

Burnard P, Harrison D, Turner G, Nesbitt R (2003) Degassing and contamination of noble gases in Mid-Atlantic Ridge basalts. Geochem Geophys Geosyst. doi:10.1029/2002GC000326

Castro J, Manga M, Martin MC (2005) Vesiculation rates of obsidian domes inferred from $\mathrm{H}_{2} \mathrm{O}$ concentration profiles. Geophys Res Lett 32:L21307

Crank J (1975) The mathematics of diffusion, 2nd edn. Oxford University Press, Oxford, p 414

Davydov MN (2012) Nucleation and growth of a gas bubble in magma. J Appl Mech Techn Phys 53:324-332

de Moor JM, Fischer TP, Sharp ZD, King PL, Wilke M, Botcharnikov RE, Cottrell E, Marty B, Klimm K, Rivard C, Ayalew D (2013) Sulfur degassing at Erta Ale (Ethiopia) and Masaya (Nicaragua) volcanoes: implications for degassing processes and oxygen fugacities of basaltic systems. Geochem Geophys Geosyst 14:4076-4108

Fortin M-A, Stern R, Watson EB (2016) Isotopic fractionation of chlorine during chemical diffusion in a dacitic melt and its implications for isotope behavior during bubble growth (abstract), 2016 Fall AGU Meeting

Gardner JE, Hilton M, Carroll MR (1999) Experimental constraints on degassing of magma: isothermal bubble growth during continuous decompression from high pressure. Earth Planet Sci Lett 168:201-218 
Gerlach TM, Taylor BE (1990) Carbon isotope constraints on degassing of carbon dioxide from Kilauea Volcano. Geochim Cosmochim Acta 54:2051-2058

Gonnermann HM, Manga M (2005) Nonequilibrium magma degassing: results from modeling of the ca. 1340 A.D. eruption of Mono Craters, California. Earth Planet Sci Lett 238:1-16

Gonnermann HM, Manga M (2007) The fluid mechanics inside a volcano. Annu Rev Fluid Mech 39:321-356

Gonnermann HM, Mukhopadhyay S (2007) Non-equilibrium degassing and a primordial source for helium in ocean-island volcanism. Nature 449:1037-1040

Halbach H, Chatterjee ND (1982) An empirical Redlich-Kwong equation of state for water to $1000{ }^{\circ} \mathrm{C}$ and $200 \mathrm{kbar}$. Contrib Mineral Petrol 79:337-345

Hess K-U, Dingwell DB (1996) Viscosities of hydrous leucogranitic melts: a non-Arrhenian model. Am Min 81:1297-1300

Jambon A (1980) Isotopic fractionation-a kinetic model for crystals growing from magmatic melts. Geochim Cosmochim Acta 44:1373-1380

Javoy M, Pineau F, Iiyama I (1978) Experimental determination of the isotopic fractionation between gaseous $\mathrm{CO}_{2}$ and carbon dissolved in tholeiitic magma. Contrib Miner Petrol 67:35-39

Johnson MC, Anderson AT, Rutherford MJ (1994) Pre-eruptive volatile contents of magmas. In: Holloway MR, Carroll JR (eds) Volatiles in Magmas, Reviews in Mineralogy v. 30, pp 281-330, Mineralogical Society of America

Kerr RC (1995) Convective crystal dissolution. Contrib Miner Petrol 121:237-246

Kurz MD, Jenkins WJ (1981) The distribution of helium in oceanic basalt glasses, Earth Planet. Sci Lett 53:41-54

Lensky NG, Navon O, Lyachovsky V (2004) Bubble growth during decompression of magma: experimental and theoretical investigation. J Volcanol Geothermal Res 129:7-22

Lesher CE, Hervig RL, Tinker D (1996) Self-diffusion of networkformers (silicon and oxygen) in naturally occurring basaltic liquid. Geochim Cosmochim Acta 60:405-413

Liu Y, Zhang Y (2000) Bubble growth in rhyolitic melt. Earth Planet Sci Lett 181:251-264

Lux G (1987) The behavior of noble gases in silicate liquids: solution, diffusion, bubbles and surface effects, with applications to natural samples. Geochim Cosmochim Acta 51:1549-1560

McIntosh IM, Llewellin EW, Humphreys MCS, Nichols ARL, Burgisser A, Schipper CI, Larsen JF (2014) Distribution of dissolved water in magmatic glass records growth and resorption of bubbles. Earth Planet Sci Lett 401:1-11

Murase T, McBirney AR (1973) Properties of some common igneous rocks and their melts at high temperatures. Geol Soc Am Bull 84:3563-3592

Navon O, Chekhmir A, Lyakhovsky V (1998) Bubble growth in highly viscous melts: theory, experiments, and autoexplosivity of dome lavas. Earth Planet Sci Lett 160:763-776

Newman S, Lowenstern JB (2002) VolatileCalc: a silicate melt- $\mathrm{H}_{2} \mathrm{O}-$ $\mathrm{CO}_{2}$ solution model written in visual basic for excel. Comput Geosci 28:597-604

Ozima M, Podosek FA (2002) Noble gas geochemistry, 2nd edn. Cambridge University Press, New York, p 286

Paonita A, Martelli M (2007) A new view of the $\mathrm{He}-\mathrm{Ar}-\mathrm{CO}_{2}$ degassing at mid-ocean ridges: homogeneous composition of magmas from the upper mantle. Geochim Cosmochim Acta 71:1747-1763

Proussevitch AA, Sahagian DL (1998) Dynamics and energetics of bubble growth in magmas: analytical formulation and numerical modeling. J Geophys Res 103:18223-18251

Proussevitch AA, Sahagian DL, Anderson AT (1993) Dynamics of diffusive bubble growth in magmas: isothermal case. J Geophys Res 98:22283-22307
Readey DW, Cooper AR (1966) Molecular diffusion with a moving boundary and spherical geometry. Chem Eng Sci 21:917-922

Richter FM, Liang Y, Davis AM (1999) Isotope fractionation by diffusion in molten oxides. Geochim Cosmochim Acta 63:2853-2861

Richter FM, Davis AM, DePaolo DJ, Watson EB (2003) Isotope fractionation by chemical diffusion between molten basalt and rhyolite. Geochim Cosmochim Acta 67:3905-3923

Richter FM, Watson EB, Mendybaev R, Teng FZ, Janney P (2008) Magnesium isotope fractionation in silicate melts by chemical and thermal diffusion. Geochim Cosmochim Acta 72:206-220

Richter FM, Watson EB, Mendybaev R, Dauphas N, Georg B, Watkins J, Valley JW (2009) Isotopic fractionation of the major elements of molten basalt by chemical and thermal diffusion. Geochim Cosmochim Acta 73:4250-4263

Shaw HR (1963) Obsidian-H2O viscosities at 1000 and 2000 bars in the temperature range 700 to $900{ }^{\circ} \mathrm{C}$. J Geophys Res 68:6337-6343

Shaw HR (1965) Comments on viscosity, crystal settling and convection in granitic magmas. Am J Sci 263:120-152

Smith VG, Tiller WA, Rutter JW (1955) A mathematical analysis of solute redistribution during solidification. Can J Phys $33: 723-745$

Sparks RSJ (1978) The dynamics of bubble formation and growth in magmas: a review and analysis. J Volcanol Geotherm Res 3:1-38

Sparks RSJ, Huppert HE (1984) Density changes during the fractional crystallization of basaltic magmas: fluid dynamic implications. Contrib Miner Petrol 85:300-309

Sparks RSJ, Barclay J, Jaupart C, Mader HM, Phillips JC (1994) Physical aspects of magma degassing 1. experimental and theoretical constraints on vesiculation. In: Volatiles in Magmas (MR Carroll and JR Holloway, Eds.), Reviews in Mineralogy v. 30, pp 413-445, Mineralogical Society of America

Toramaru A (1989) Vesiculation process and bubble size distribution in ascending magmas with constant velocities. J Geophys Res 94:17523-17542

Toramaru A (1995) Numerical study of nucleation and growth of bubbles in viscous magmas. J Geophys Res 100:1913-1931

Villeneuve N, Neuville DR, Boivin P, Bachèlery P, Richet P (2008) Magma crystallization and viscosity: a study of molten basalts from the Piton de la Fournaise volcano (La Réunion island). Chem Geol 256:242-251

Vlastélic I, Staudacher T, Bachèlery P, Télouk P, Neuville D, Benbakkar M (2011) Lithium isotope fractionation during magma degassing: constraints from silicic differentiates and natural gas condensates from Piton de la Fournaise volcano (Réunion Island). Chem Geol 284:26-34

Watkins J, DePaolo DJ, Huber C, Ryerson FJ (2009) Liquid composition-dependence of calcium isotope fractionation during diffusion in molten silicates. Geochim Cosmochim Acta 73:7341-7359

Watkins J, DePaolo DJ, Ryerson FJ, Petersen BT (2011) Influence of liquid structure on diffusive isotope separation in molten silicates and aqueous solutions. Geochim Cosmochim Acta 75:3103-3118

Watson EB (1981) Diffusion in magmas at depth in the Earth: the effects of pressure and dissolved $\mathrm{H}_{2} \mathrm{O}$. Earth Planet Sci Lett 52:291-301

Watson EB (1991) Diffusion of dissolved $\mathrm{CO}_{2}$ and $\mathrm{Cl}$ in hydrous silicic to intermediate magmas. Geochim Cosmochim Acta 55:1897-1902

Watson EB, Müller T (2009) Non-equilibrium isotopic and elemental fractionation during diffusion-controlled crystal growth under static and dynamic conditions. Chem Geol 267:111-124

Webster JD (1992a) MVP-melt interactions in Cl-rich granitic systems: effects of melt composition at $2 \mathrm{kbar}$ and $800^{\circ} \mathrm{C}$. Geochim Cosmochim Acta 56:659-678 
Webster JD (1992b) MVP-melt interactions involving Cl-rich granites: experimental study from 2 to 8 kbar. Geochim Cosmochim Acta 56:679-687

Webster JD, Hollway JR, Hervig RL (1989) Partitioning of lithophile trace elements between $\mathrm{H}_{2} \mathrm{O}$ and $\mathrm{H}_{2} \mathrm{O}+\mathrm{CO}_{2}$ fluids and topaz rhyolite melt. Econ Geol 84:116-134

Webster JD, Tappen CM, Mandeville CW (2009) Partitioning behavior of chlorine and fluorine in the system apatite-melt-fluid. II: felsic silicate systems at $200 \mathrm{MPa}$. Geochim Cosmochim Acta 73:559-581
Zhang Y (2008) Geochemical kinetics. Princeton University Press, Princeton, $\mathrm{p} 631$

Zhang Y, Ni H (2010) Diffusion of H, C, and O components in silicate melts. In: Diffusion in Minerals and Melts (Y Zhang and DJ Cherniak, Eds.), Reviews in Mineralogy and Geochemistry v. 72, pp 171-225, Mineralogical Society of America

Zhang Y, Ni H, Chen Y (2010) Diffusion data in silicate melts. In: Zhang Y, Cherniak DJ (eds) Diffusion in minerals and melts, reviews in mineralogy and geochemistry, Vol 72, pp 311-408, Mineralogical Society of America 